\title{
Rate-Ratio Asymptotic Analysis of the Influence of Addition of Carbon Monoxide on the Structure and Mechanisms of Extinction of Nonpremixed Methane Flames with Comparison to Experiments
}

\author{
Kalyanasundaram Seshadria ${ }^{\mathrm{a}}$, Xue-Song Bai ${ }^{\mathrm{b}}$ \\ ${ }^{a}$ Department of Mechanical and Aerospace Engineering, University of California at San \\ Diego, La Jolla, California 92093-0411, USA \\ ${ }^{b}$ Department of Energy Sciences, Lund University, S 22100 Lund, Sweden
}

\begin{abstract}
Rate-ratio asymptotic (RRA) analysis is carried out to elucidate the influence of carbon monoxide on the structure and critical conditions of extinction of nonpremixed methane flames. Steady, axisymmetric, laminar flow of two counterflowing streams toward a stagnation plane is considered. One stream, called the fuel stream is made up of a mixture of methane $\left(\mathrm{CH}_{4}\right)$ and nitrogen $\left(\mathrm{N}_{2}\right)$. The other stream, called the oxidizer stream, is a mixture of oxygen $\left(\mathrm{O}_{2}\right)$, and $\mathrm{N}_{2}$. Carbon monoxide $(\mathrm{CO})$ is added either to the oxidizer stream or to the fuel stream. Chemical reactions, represented by four global steps, are presumed to take place in a thin reaction zone. To the leading order the reactants, $\mathrm{CH}_{4}, \mathrm{O}_{2}$, and $\mathrm{CO}$ are completely consumed in the reaction zone. On either side of this thin reaction zone, the flow field is inert. These inert regions represent the outer structure of the flame. The outer structures provide matching conditions required for predicting the structure of the reaction zone. In the reaction zone, chemical reactions are presumed to take place in two layers - the inner layer and the oxidation layer. The scalar dissipation


rate at extinction is predicted from results of the asymptotic analysis and compared with previous measurements and computational predictions using detailed chemistry. The predictions of the asymptotic analysis are found to agree well with the experimental data for $\mathrm{CO}$ addition to the fuel stream, and for small amounts of $\mathrm{CO}$ addition to the oxidizer stream. For large amounts of $\mathrm{CO}$ addition to the oxidizer stream, the approximations introduced in the asymptotic analysis become inaccurate. A key finding is that with increasing amounts of $\mathrm{CO}$ added to the oxidizer stream the scalar dissipation rate at extinction first increases and then decreases. It is attributed to changes in location of the inner layer within the reaction zone.

Keywords: rate-ratio asymptotic analysis, flame structure, extinction, methane flames, carbon monoxide addition

\section{Introduction}

Starting from the pioneering work of Peters and Williams [1] on rate-ratio asymptotic (RRA) analysis of premixed methane flames, many studies have addressed fundamental aspects of the structure of premixed and nonpremixed flames using RRA analysis [2-15]. These analysis employed reduced mechanisms that were obtained employing a systematic procedure developed by Peters [3]. The present RRA analysis is focused on elucidating the influence of carbon monoxide $(\mathrm{CO})$ on the structure and extinction of nonpremixed methane flames.

Studies on combustion of mixtures made up of several reactants are of 
fundamental and practical importance. The practical importance of these studies emanates from a need to characterize combustion processes taking place in practice where the fuel is made up of several components that include methane and carbon monoxide. The present investigation is motivated by a previous experimental and computational study of the influence of carbon monoxide ( $\mathrm{CO}$ ) on the structure and critical conditions of extinction of nonpremixed methane $\left(\mathrm{CH}_{4}\right)$ flames [16]. In this previous study, a Burke-Schumann (flame-sheet) formulation was applied to laminar counterflow diffusion-flame experiments in which, $\mathrm{CO}$ was added either to the fuel stream, made up of mixtures of methane and nitrogen $\left(\mathrm{N}_{2}\right)$, or to the oxidizer stream, made up of mixtures of oxygen $\left(\mathrm{O}_{2}\right)$ and nitrogen, with both streams at normal atmospheric pressure and at normal room temperature. Experimental conditions were adjusted to fix selected values of the stoichiometric mixture fraction and the adiabatic flame temperature, and the strain rate was increased gradually until extinction occurred. At these selected sets of values, the strain rate at extinction was measured as a function of the $\mathrm{CO}$ concentration in the fuel or oxidizer stream [16]. It was found that with increasing amounts of $\mathrm{CO}$ in the oxidizer stream, the strain rate at extinction first increased and then decreased. With increasing amounts of $\mathrm{CO}$ in the fuel stream, changes in values of the strain rate at extinction was small in comparison to those measured for $\mathrm{CO}$ addition to the oxidizer stream. The experimental results were in agreement with predictions obtained employing detailed chemistry [16]. The main goal of the present RRA analysis is to elucidate the effect of $\mathrm{CO}$ addition on the structure of the reaction zone of nonpremixed methane flames, and highlight its influence on critical condi- 
tions of extinction.

The analysis described here complements a previous RRA analysis of the influence of hydrogen $\left(\mathrm{H}_{2}\right)$ on the structure of nonpremixed methane-flames [17]. It is carried out using a reduced four-step chemical kinetic mechanism that is described in Sec. 5. Critical conditions of extinction were predicted from results of the asymptotic analysis and were found to agree well with measurements [18]. Addition of hydrogen to methane flames was found to promote combustion by delaying extinction. An important finding of the previous asymptotic analysis was that the mechanisms by which hydrogen promotes combustion when it is added to the oxidizer stream is different from that when it is added to the fuel stream [17]. The present rate-ratio asymptotic analysis seeks to obtain a similar fundamental understanding of the influence of $\mathrm{CO}$ on nonpremixed methane flames. In particular the present analysis seeks to elucidate the similarities and differences in flame structures and mechanisms of extinction between CO addition to the fuel stream and $\mathrm{CO}$ addition to the oxidizer stream.

\section{Formulation}

Steady, axisymmetric, laminar flow of two counterflowing streams toward a stagnation plane is considered here. The origin of co-ordinates is placed at the stagnation point. The fuel stream is made up of $\mathrm{CH}_{4}$ and $\mathrm{N}_{2}$ and the oxidizer stream, is made up of $\mathrm{O}_{2}$, and $\mathrm{N}_{2}$. Carbon monoxide is added either to the fuel stream or to the oxidizer stream. The mass fraction of $\mathrm{CH}_{4}$ in the fuel stream is $Y_{\mathrm{F}, 1}$, and that of $\mathrm{O}_{2}$ in the oxidizer stream is $Y_{\mathrm{O}_{2}, 2}$. 
The temperature of the fuel stream is $T_{1}$ and the temperature of the oxidizer stream is $T_{2}$. When $\mathrm{CO}$ is added to the fuel stream its mass fraction is $Y_{\mathrm{CO}, 1}$ and it is $Y_{\mathrm{CO}, 2}$ when added to the oxidizer stream. Subscript 1 refers to conditions in the fuel stream and subscript 2 to conditions in the oxidizer stream. The flow-field is characterized by the strain rate, $a$, defined as the normal gradient of the normal component of the flow velocity on the oxidizer side of the stagnation plane $[19,20]$. The analysis employs a conserved scalar $\xi$, the mixture fraction, as the independent variable. This quantity is defined to satisfy a source-free conservation equation, $\rho(\vec{v} \cdot \vec{\nabla}) \vec{v}-\vec{\nabla} \cdot\left[\left(\lambda / c_{\mathrm{p}}\right) \vec{\nabla} \xi\right]=$ 0 , with $\xi=0$ in the oxidizer stream far from the stagnation plane and $\xi=$ 1 in the fuel stream [21-23]. Here $\vec{v}$ is the velocity vector, $\lambda$ is the thermal conductivity, $\rho$ the density, and $c_{\mathrm{p}}$ the heat capacity per unit mass of the mixture. A characteristic diffusion time, $\chi^{-1}$, is given by

$$
\chi=2\left[\lambda /\left(\rho c_{p}\right)\right]|\nabla \xi|^{2}
$$

The quantity $\chi$, termed the scalar dissipation rate [7, 21], varies with $\xi[24]$. In the analysis the Lewis number, $L e_{\mathrm{i}}=\lambda /\left(\rho c_{\mathrm{p}} D_{\mathrm{i}}\right)$, of the reactants, $\mathrm{CH}_{4}, \mathrm{O}_{2}$ and $\mathrm{CO}$, the main products, carbon dioxide $\left(\mathrm{CO}_{2}\right)$ and water vapor $\left(\mathrm{H}_{2} \mathrm{O}\right)$, and $\mathrm{N}_{2}$ are presumed to be equal to unity [25]. Here $D_{\mathrm{i}}$ is the coefficient of diffusion of species $i$. For convenience the definitions

$$
\begin{aligned}
X_{\mathrm{i}} & \equiv Y_{\mathrm{i}} W_{\mathrm{N}_{2}} / W_{\mathrm{i}} \\
\tau & \equiv c_{\mathrm{p}} W_{\mathrm{N}_{2}}\left(T-T_{\mathrm{u}}\right) / Q_{\mathrm{F}},
\end{aligned}
$$

are introduced. Here, $Q_{\mathrm{F}}$ is the heat released per mole of $\mathrm{CH}_{4}$ consumed in the overall step $\mathrm{CH}_{4}+2 \mathrm{O}_{2} \rightarrow \mathrm{CO}_{2}+2 \mathrm{H}_{2} \mathrm{O}, W_{\mathrm{i}}$ is the molecular weight of species $i$, and $T_{\mathrm{u}}=T_{2}+\left(T_{1}-T_{2}\right) \xi$. It follows that, $X_{\mathrm{i}}=C_{i} W_{\mathrm{N}_{2}} / \rho$, where 
$C_{i}$ is the molar concentration of species $i$. At $298 \mathrm{~K}, Q_{\mathrm{F}}=803000 \mathrm{~J} / \mathrm{mol}[26]$.

The RRA analysis is carried out employing a reduced four step mechanism [13]. The Damköhler numbers constructed using the flow time obtained from the scalar dissipation rate, and the chemical time obtained from the rate parameters for the four-step mechanism are presumed to be large. In this asymptotic limit, chemical reactions are presumed to take place in a thin reaction zone. For complete consumption of all reactants, the reaction zone is located at $\xi=\xi_{\text {st }}$, where $\xi_{\text {st }}$ is the stoichiometric fraction. The adiabatic temperature at $\xi_{\mathrm{st}}$ is represented by $T_{\mathrm{st}}$. The values of $\xi_{\mathrm{st}}$ and $T_{\mathrm{st}}$ obtained from element balance and energy conservation for $L e_{\mathrm{i}}=1$ are described in Sec. 4.1 and are given by

$$
\begin{aligned}
& \xi_{\mathrm{st}}=\left(2 X_{\mathrm{O}_{2}, 2}-X_{\mathrm{CO}, 2}\right) /\left(2 X_{\mathrm{O}_{2}, 2}-X_{\mathrm{CO}, 2}+X_{\mathrm{CO}, 1}+4 X_{\mathrm{F}, 1}\right), \\
& \tau_{\mathrm{st}}=X_{\mathrm{F}, 1} \xi_{\mathrm{st}}+q X_{\mathrm{CO}, 2}+q\left(X_{\mathrm{CO}, 1}-X_{\mathrm{CO}, 2}\right) \xi_{\mathrm{st}} .
\end{aligned}
$$

Here, $\tau_{\mathrm{st}}=c_{\mathrm{p}} W_{\mathrm{N}_{2}}\left(T_{\mathrm{st}}-T_{\mathrm{ref}}\right) / Q_{\mathrm{F}}, q=Q_{\mathrm{CO}} / Q_{\mathrm{F}}$, and $Q_{\mathrm{CO}}$ is the heat released per mole of $\mathrm{CO}$ consumed in the overall step $\mathrm{CO}+(1 / 2) \mathrm{O}_{2} \rightarrow \mathrm{CO}_{2}$. At $298 \mathrm{~K} Q_{\mathrm{CO}}=283000 \mathrm{~J} / \mathrm{mol}[26]$, and $q=0.353$. For convenience a quantity $r$ is defined as

$$
r=X_{\mathrm{O}_{2}, 2}\left(1-\xi_{\mathrm{st}}\right) /\left(2 X_{\mathrm{F}, 1} \xi_{\mathrm{st}}\right)-1 .
$$

It can be readily verified that the quantity $r$ represents the ratio of the fraction of the flux of oxygen that consumes $\mathrm{CO}$ to the fraction that consumes methane. It is identical to the quantity $r$ defined in previous studies on the influence of hydrogen on the structure and extinction of methane flames $[17,18]$. 


\section{Numerical Computation of Flame Structure}

To guide the asymptotic analysis, flame structures were calculated using the San Diego Mechanism [27, 28] employing a kinetic scheme made up of 470 elementary reactions among 53 species. Computations were performed with the temperatures at the boundaries $T_{1}=T_{2}=298 \mathrm{~K}$, the pressure equal to $1 \mathrm{~atm}$ with either, $Y_{\mathrm{CO}, 2}=0$, or $Y_{\mathrm{CO}, 1}=0$. The procedure for selecting the boundary values of the reactants, $Y_{\mathrm{F}, 1}, Y_{\mathrm{CO}, 1}, Y_{\mathrm{O}_{2}, 2}$, and $Y_{\mathrm{CO}, 2}$, is similar to that employed in the previous experimental and computational investigation of the influence of $\mathrm{CO}$ on structure and extinction of nonpremixed methane flames [16]. Equation (3) provides two relations among the four parameters, $Y_{\mathrm{F}, 1}, Y_{\mathrm{CO}, 1}, Y_{\mathrm{O}_{2}, 2}$, and $Y_{\mathrm{CO}, 2}$. For $\mathrm{CO}$ addition to the oxidizer stream (with $\left.Y_{\mathrm{CO}, 1}=0\right)$ at a selected value of $Y_{\mathrm{CO}, 2}$, the values for $Y_{\mathrm{F}, 1}$, and $Y_{\mathrm{O}_{2}, 2}$, were so chosen that $\xi_{\mathrm{st}}$ and $T_{\mathrm{st}}$ calculated using Eq. (3), respectively, are 0.055, and $2000 \mathrm{~K}$. It follows that $Y_{\mathrm{N}_{2}, 2}=1-Y_{\mathrm{O}_{2}, 2}-Y_{\mathrm{CO}, 2}$, and $Y_{\mathrm{N}_{2}, 1}=1-Y_{\mathrm{F}, 1}$. A similar procedure was employed for $\mathrm{CO}$ addition to the fuel stream (with $\left.Y_{\mathrm{CO}, 2}=0\right)$. Computations were performed using Chemkin-Pro [29]. The calculations employ mixture-average diffusion including Soret effects and heat losses by radiation.

Figures 1, 2, and 3, show profiles of mass fractions of the reactants, hydrogen $\left(\mathrm{H}_{2}\right)$ and temperature, $T$ as a function of $\xi$. Figure 1 shows flame structure for $\mathrm{CO}$ addition to the fuel stream, and Figs. 2, and 3 show flame structures for $\mathrm{CO}$ addition to the oxidizer stream. The cases for $\mathrm{CO}$ addition to the oxidizer stream have nearly the same extinction strain rates and are on either side of the peak extinction strain rate shown in Fig. 2 of Ref. [16]. The 
Figure 1: Predicted profile of temperature, and profiles of mass fractions of $\mathrm{CH}_{4}, \mathrm{CO}, \mathrm{O}_{2}$, $\mathrm{H}_{2}$ and as a function of $\xi$ with $\mathrm{CO}$ addition to the fuel stream $\left(Y_{\mathrm{CO}, 1}=0.16, T_{\mathrm{st}}=2000 \mathrm{~K}\right.$, $\xi_{\text {st }}=0.055$, and strain rate $\left.a=127 \mathrm{~s}^{-1}\right)$.

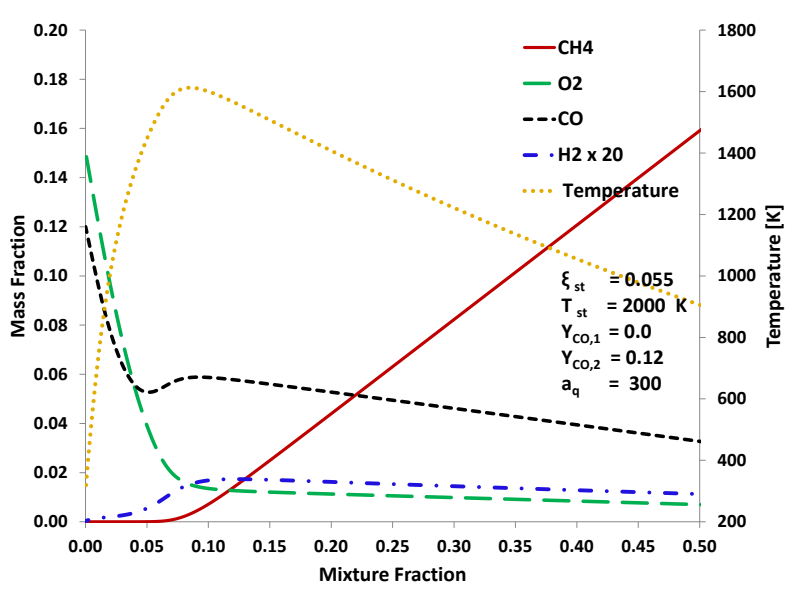

Figure 2: Predicted profile of temperature, and profiles of mass fractions of $\mathrm{CH}_{4}, \mathrm{CO}$, $\mathrm{O}_{2}, \mathrm{H}_{2}$ and as a function of $\xi$ with $\mathrm{CO}$ addition to the oxidizer stream $\left(Y_{\mathrm{CO}, 2}=0.12\right.$, $T_{\mathrm{st}}=2000 \mathrm{~K}, \xi_{\mathrm{st}}=0.055$, and strain rate $\left.a=300 \mathrm{~s}^{-1}\right)$. 
Figure 3: Predicted profile of temperature, and profiles of mass fractions of $\mathrm{CH}_{4}, \mathrm{CO}$, $\mathrm{O}_{2}, \mathrm{H}_{2}$ and as a function of $\xi$ with $\mathrm{CO}$ addition to the oxidizer stream $\left(Y_{\mathrm{CO}, 2}=0.19\right.$, $T_{\mathrm{st}}=2000 \mathrm{~K}, \xi_{\mathrm{st}}=0.055$, and strain rate $\left.a=302 \mathrm{~s}^{-1}\right)$.

profiles in Figs. 1, 2, and 3 show that $\mathrm{CH}_{4}$ is completely consumed. It is well known that $\mathrm{CO}$ and $\mathrm{H}_{2}$ are formed from consumption of $\mathrm{CH}_{4}[1,3,8,13,16]$. Figures 1, 2, and 3 show that the mass fraction of $\mathrm{H}_{2}, Y_{\mathrm{H}_{2}}$, is small, its peak value is attained in the vicinity of the region where $\mathrm{CH}_{4}$ is consumed, indicating that it is formed in this region, and it is primarily consumed on the left side of its peak value. The profile of mass fraction of $\mathrm{CO}, Y_{\mathrm{CO}}$ in Fig. 2 has a maximum in the vicinity of the region where $\mathrm{CH}_{4}$ is consumed again indicating that it is formed in this region. This maximum is also seen for the larger amount of $\mathrm{CO}$ addition to the oxidizer stream in Fig. 3, while the minima seen in Figs. 2 and 3 are not observed for CO addition to the fuel stream in Fig. 1, although it is still produced from consumption of $\mathrm{CH}_{4}$ as shown in Fig. 5 of Ref. [16]. In all cases consumption of CO takes place in the region where $\mathrm{H}_{2}$ is consumed. More detailed descriptions of rates of consumption of various species including those described here are given in 
Ref. [16].

A noteworthy observation concerns the value of the mass fraction of $\mathrm{CH}_{4}$, $\mathrm{CO}, \mathrm{O}_{2}$, and $\mathrm{H}_{2}$ at the stoichiometric mixture fraction, $\xi_{\mathrm{st}}=0.055$. The mass fractions of $\mathrm{CH}_{4}, \mathrm{O}_{2}$, and $\mathrm{CO}$ at $\xi_{\text {st }}=0.055$ is a measure of leakage of these reactants from the reaction zone. Comparison of the values of the mass fractions of these species at $\xi_{\text {st }}=0.055$ in Fig. 2 and Fig. 3 show that the mass fractions of $\mathrm{CH}_{4}$ and $\mathrm{H}_{2}$ decrease with increasing $Y_{\mathrm{CO}, 2}$, while those of $\mathrm{O}_{2}$ and $\mathrm{CO}$ increase. To further illustrate this trend, Fig. 4 shows the

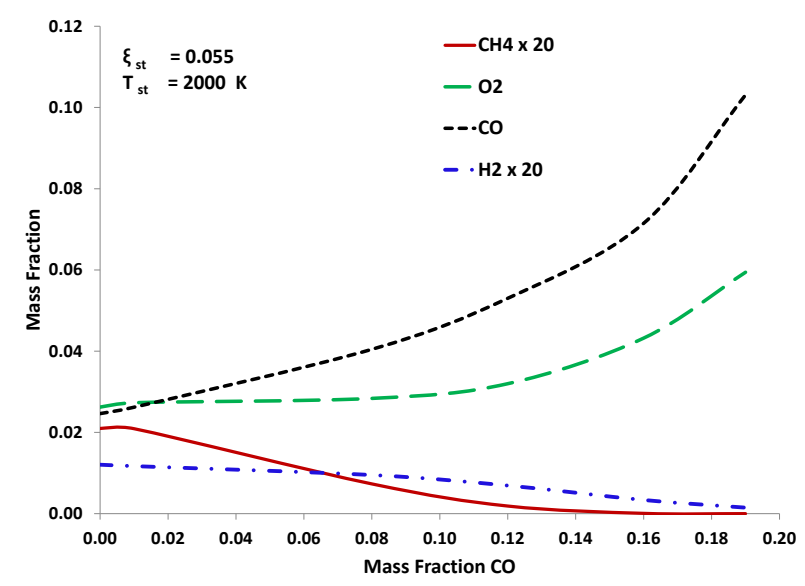

Figure 4: Predicted values of mass fractions of $\mathrm{CH}_{4}, \mathrm{CO}, \mathrm{O}_{2}$, and $\mathrm{H}_{2}$ at $\xi_{\mathrm{st}}=0.055$ as a function of mass fraction of $\mathrm{CO}$ in the oxidizer stream, $Y_{\mathrm{CO}, 2}$ at conditions close to flame extinction.

leakage of $\mathrm{CH}_{4}, \mathrm{O}_{2}$, and $\mathrm{CO}$ from the reaction zone for $\mathrm{CO}$ addition to the oxidizer stream. With increasing values of $Y_{\mathrm{CO}, 2}$ mass fractions of $\mathrm{CH}_{4}$ and $\mathrm{H}_{2}$ decrease while the mass fractions of $\mathrm{O}_{2}$ and $\mathrm{CO}$ increase. This indicates that fuel and $\mathrm{H}_{2}$ are completely consumed. The mass fractions of $\mathrm{CO}$ and $\mathrm{O}_{2}$ at $\xi_{\text {st }}$ increase with increasing $Y_{\mathrm{CO}, 2}$. The increase for $\mathrm{CO}$ is much larger 
than that for $\mathrm{O}_{2}$. Thus there is significant increase in leakage of $\mathrm{O}_{2}$ and $\mathrm{CO}$ from the reaction zone with increasing $Y_{\mathrm{CO}, 2}$. For $\mathrm{CO}$ addition to the fuel stream the mass fraction of $\mathrm{CO}$ and $\mathrm{O}_{2}$ at $\xi_{\text {st }}$ was small and did not change much with increasing $Y_{\mathrm{CO}, 1}$. Thus for $\mathrm{CO}$ addition to the fuel stream, there was very little leakage of $\mathrm{O}_{2}$ and $\mathrm{CO}$ from the reaction zone. In summary, the computational results show that for all levels of $\mathrm{CO}$ addition to the fuel stream and to the oxidizer stream, $\mathrm{CH}_{4}$ and $\mathrm{H}_{2}$, formed in the reaction zone, are completely consumed. For small amounts of CO addition to the oxidizer stream, the leakage of $\mathrm{CO}$ and $\mathrm{O}_{2}$ from the reaction zone is small, while the leakage of these quantities increase with increasing $Y_{\mathrm{CO}, 2}$. For $\mathrm{CO}$ addition to the fuel stream the leakage of $\mathrm{CO}$ and $\mathrm{O}_{2}$ is small. These observations are used as a guide in the asymptotic analysis.

\section{Asymptotic Flame Structure}

The asymptotic structure of the flame is presumed to be made up a thin reaction zone where chemical reactions take place. The regions on either sides of the reaction zone are inert and represent the outer structure. Analysis of the outer structure provides boundary conditions for the differential equations that describe the structure of the reaction zone. Analysis of the reaction zone gives the scalar dissipation rate at extinction. In view of the differences in flame structure described in the previous section, the present RRA analysis is restricted to prediction of flame structures and critical conditions of extinction for all levels of $\mathrm{CO}$ addition to the fuel stream, and for small amounts of $\mathrm{CO}$ addition to the oxidizer stream. The analysis for the outer structure is shown in the next section. This is followed by analysis of 
the reaction zone.

\subsection{Outer Structure}

The temperature profile and profiles of mass fractions of the reactants, $\mathrm{CH}_{4}, \mathrm{O}_{2}$, and $\mathrm{CO}$, and the products carbon dioxide $\left(\mathrm{CO}_{2}\right)$ and water-vapor $\left(\mathrm{H}_{2} \mathrm{O}\right)$ are obtained employing the flamesheet approximation. Conservation of the element carbon, hydrogen and oxygen gives the following relations

$$
\begin{aligned}
& X_{\mathrm{F}}+X_{\mathrm{CO}_{2}}+X_{\mathrm{CO}}=X_{\mathrm{CO}, 2}(1-\xi)+\left(X_{\mathrm{F}, 1}+X_{\mathrm{CO}, 1}\right) \xi \\
& 2 X_{\mathrm{F}}+X_{\mathrm{H}_{2} \mathrm{O}}=2 X_{\mathrm{F}, 1} \xi \\
& 2 X_{\mathrm{O}_{2}}+X_{\mathrm{CO}}+2 X_{\mathrm{CO}_{2}}+X_{\mathrm{H}_{2} \mathrm{O}}=\left(2 X_{\mathrm{O}_{2}, 2}+X_{\mathrm{CO}, 2}\right)(1-\xi)+X_{\mathrm{CO}, 1} \xi .
\end{aligned}
$$

Energy conservation gives

$$
\begin{aligned}
& \sum_{i} X_{\mathrm{i}} H_{\mathrm{i}}-\left[X_{\mathrm{F}, 1} H_{\mathrm{F}}\left(T_{\mathrm{u}}\right)+X_{\mathrm{CO}, 1} H_{\mathrm{CO}}\left(T_{\mathrm{u}}\right)\right] \xi- \\
& {\left[X_{\mathrm{O}_{2}, 2} H_{\mathrm{O}_{2}}\left(T_{\mathrm{u}}\right)+X_{\mathrm{CO}, 2} H_{\mathrm{CO}}\left(T_{\mathrm{u}}\right)\right](1-\xi)=0 .}
\end{aligned}
$$

Here $H_{\mathrm{i}}(T)$ is the molar enthalpy of species $i$. The caloric equation is $H_{\mathrm{i}}(T)=H_{\mathrm{i}}\left(T_{\text {ref }}\right)+W_{\mathrm{i}} \int_{T_{\mathrm{ref}}}^{T} c_{\mathrm{p}, \mathrm{i}} d T$, where $c_{\mathrm{p}, \mathrm{i}}$ is the heat capacity per unit mass of species $i$, and $T_{\text {ref }}$ is the reference temperature. In the present formulation $T_{\text {ref }}=T_{\mathrm{u}}=T_{1}=T_{2}$.

Figure 5 is a schematic illustration of the outer structure. It shows the temperature profile and profiles of the reactants. The reaction zone is located at $\xi=\xi_{\text {st }}$ where all reactants are completely consumed to the leading order and the adiabatic temperature is $T_{\text {st }}$. The value of $\xi_{\text {st }}$ obtained by setting $X_{\mathrm{F}}=X_{\mathrm{O}_{2}}=X_{\mathrm{CO}}=0$ in Eq. (5) is given by the first relation in Eq. (3). The presumed profiles of reactants is consistent with the profiles of these species 
Figure 5: Schematic illustration of the outer structure with CO addition to the fuel stream and to the oxidizer stream.

shown in Figs. 1, 2 and 4.

The values of $X_{\mathrm{H}_{2} \mathrm{O}}$ and $X_{\mathrm{CO}_{2}}$ at $\xi_{\text {st }}$ obtained by setting $X_{\mathrm{F}}=X_{\mathrm{O}_{2}}=$ $X_{\mathrm{CO}}=0$ in Eq. (5) are

$$
\begin{aligned}
& X_{\mathrm{CO}_{2}, \mathrm{st}}=X_{\mathrm{CO}, 2}+\left(X_{\mathrm{CO}, 1}-X_{\mathrm{CO}, 2}\right) \xi_{\mathrm{st}}+X_{\mathrm{F}, 1} \xi_{\mathrm{st}}, \\
& X_{\mathrm{H}_{2} \mathrm{O}, \mathrm{st}}=2 X_{\mathrm{F}, 1} \xi_{\mathrm{st}}
\end{aligned}
$$

where the subscript st refers to quantities evaluated at $\xi_{\mathrm{st}}$. The mass fraction of $\mathrm{N}_{2}$ at $\xi_{\mathrm{st}}$ is $X_{\mathrm{N}_{2}, \mathrm{st}}=Y_{\mathrm{N}_{2}, \mathrm{st}}=1-\sum_{i} X_{\mathrm{i}, \mathrm{st}} W_{\mathrm{i}} / W_{\mathrm{N}_{2}}$. The adiabatic temperature $T_{\text {st }}$ obtained from Eq. (6) is given by the second relation in Eq. (3), where $c_{\mathrm{p}}\left(T_{\mathrm{st}}-T_{\mathrm{u}}\right) \equiv \sum_{i} \int_{T_{\mathrm{u}}}^{T_{\mathrm{st}}}\left(Y_{\mathrm{i}, \mathrm{st}} c_{\mathrm{p}, \mathrm{i}}\right) d T$. The gradients of $\tau$ and $X_{\mathrm{i}}$ with respect to $\xi$ are discontinuous at $\xi_{\text {st }}$. These gradients in the region $\xi>\xi_{\text {st }}$ are represented by the subscript + , and in the region $\xi<\xi_{\text {st }}$ by the subscript 
-. The gradients at $\xi_{\mathrm{st}+}$ are

$$
\begin{aligned}
& d X_{\mathrm{F}} / d \xi=X_{\mathrm{F}, 1} /\left(1-\xi_{\mathrm{st}}\right)=g, \quad d X_{\mathrm{O}_{2}} / d \xi=0, \\
& d X_{\mathrm{CO}} / d \xi=X_{\mathrm{CO}, 1} /\left(1-\xi_{\mathrm{st}}\right)=m, \quad d X_{\mathrm{CO}_{2}} / d \xi=-X_{\mathrm{CO}_{2}, \mathrm{st}} /\left(1-\xi_{\mathrm{st}}\right), \\
& d X_{\mathrm{H}_{2} \mathrm{O}} / d \xi=-X_{\mathrm{H}_{2} \mathrm{O}, \mathrm{st}} /\left(1-\xi_{\mathrm{st}}\right), \quad d \tau / d \xi=-\tau_{\mathrm{st}} /\left(1-\xi_{\mathrm{st}}\right)=-p .
\end{aligned}
$$

At $\xi_{\text {st_ }}$ the gradients are

$$
\begin{aligned}
& d X_{\mathrm{F}} / d \xi=0, \quad d X_{\mathrm{O}_{2}} / d \xi=-X_{\mathrm{O}_{2}, 2} / \xi_{\mathrm{st}}=-2 b, \\
& d X_{\mathrm{CO}} / d \xi=-X_{\mathrm{CO}, 2} / \xi_{\mathrm{st}}=-n, \quad d X_{\mathrm{CO}_{2}} / d \xi=X_{\mathrm{CO}_{2}, \mathrm{st}} / \xi_{\mathrm{st}} \\
& d X_{\mathrm{H}_{2} \mathrm{O}} / d \xi=X_{\mathrm{H}_{2} \mathrm{O}, \mathrm{st}} / \xi_{\mathrm{st}}, \quad d \tau / d \xi=\tau_{\mathrm{st}} / \xi_{\mathrm{st}}=s .
\end{aligned}
$$

For given values of $X_{\mathrm{F}, 1}, X_{\mathrm{O}_{2}, 2}, X_{\mathrm{CO}, 1}, X_{\mathrm{CO}, 2}, T_{1}$, and $T_{2}$, Eqs. (3), (5), and (7) can be used to construct the outer structure shown in Fig. 5.

\section{The Reduced Mechanism}

The four-step reduced mechanism that is employed to describe the chemical reactions taking place in the thin reaction zone is identical to that used in previous analysis $[13,17]$. A concise description of this mechanism is given here. The four-step mechanism is

$$
\begin{aligned}
& \mathrm{CH}_{4}+2 \mathrm{H}+\mathrm{H}_{2} \mathrm{O} \rightleftharpoons \mathrm{CO}+4 \mathrm{H}_{2}, \quad \mathrm{I} \\
& \mathrm{CO}+\mathrm{H}_{2} \mathrm{O} \rightleftharpoons \mathrm{CO}_{2}+\mathrm{H}_{2}, \quad \text { II } \\
& \mathrm{H}+\mathrm{H}+\mathrm{M} \rightarrow \mathrm{H}_{2}+\mathrm{M}, \quad \mathrm{III} \\
& \mathrm{O}_{2}+3 \mathrm{H}_{2} \rightleftharpoons 2 \mathrm{H}+2 \mathrm{H}_{2} \mathrm{O}, \quad \mathrm{IV}
\end{aligned}
$$

Table 1 shows the elementary reactions that are used in the analysis. The rate data is the same as that in the San Diego Mechanism [27, 28]. The symbol $f$ appearing in the first column of Table 1 refers to the forward 
Table 1: Rate data. Units are moles, cubic centimeters, seconds, kJoules, Kelvin.

\begin{tabular}{|c|c|c|c|c|c|c|}
\hline \multirow{2}{*}{$\frac{\text { Number }}{1 \mathrm{f}}$} & \multicolumn{3}{|c|}{ Reaction } & \multirow{2}{*}{$\frac{B_{n}}{3.520 \times 10^{16}}$} & \multirow{2}{*}{$\frac{\alpha_{n}}{-0.700}$} & \multirow{2}{*}{$\frac{E_{n}}{71.420}$} \\
\hline & \multicolumn{3}{|r|}{$\mathrm{OH}+\mathrm{O}$} & & & \\
\hline \multirow[t]{2}{*}{5} & \multirow[t]{2}{*}{$\mathrm{H}+\mathrm{O}_{2}+\mathrm{M}$} & \multirow[t]{2}{*}{$\rightarrow$} & \multirow{2}{*}{$\begin{array}{r}\mathrm{HO}_{2}+\mathrm{M} \quad k \\
k\end{array}$} & $5.750 \times 10^{19}$ & -1.400 & 0.000 \\
\hline & & & & $4.65 \times 10^{12}$ & 0.440 & 0.000 \\
\hline $6 f$ & $\mathrm{CO}+\mathrm{OH}$ & $\rightarrow$ & $\mathrm{CO}_{2}+\mathrm{H}$ & $4.400 \times 10^{6}$ & 1.50 & -3.100 \\
\hline $7 \mathrm{f}$ & $\mathrm{CH}_{4}+\mathrm{H}$ & $\rightarrow$ & $\mathrm{CH}_{3}+\mathrm{H}_{2}$ & $1.300 \times 10^{4}$ & 3.000 & 33.360 \\
\hline \multirow[t]{2}{*}{8} & \multirow[t]{2}{*}{$\mathrm{CH}_{3}+\mathrm{H}+\mathrm{M}$} & \multirow[t]{2}{*}{$\rightarrow$} & \multirow[t]{2}{*}{$\mathrm{CH}_{4}+\mathrm{M}$} & $2.47 \times 10^{23}$ & -4.760 & 10.209 \\
\hline & & & & $1.27 \times 10^{16}$ & -0.630 & 1.602 \\
\hline 9 & $\mathrm{CH}_{3}+\mathrm{O}$ & $\rightarrow$ & $\mathrm{CH}_{2} \mathrm{O}+\mathrm{H}$ & $8.43 \times 10^{13}$ & 0.000 & 0.000 \\
\hline
\end{tabular}

step of a reversible elementary reaction $n$, and subscript $b$ later will refer to the reverse step. Reactions 5, 8, and 9, are presumed to be irreversible. The rate constant of elementary step $n$ is $k_{n}=B_{n} T^{\alpha_{n}} \exp \left[-E_{n} /(\widehat{R} T)\right]$, where $\widehat{R}$ is the universal gas constant. The equilibrium constants for the reversible reactions 1,6 , and 7 , respectively, are $K_{1}=13.89 \times \exp (-7964 / T)$, $K_{6}=6.73 \times 10^{-3} \times \exp (11323 / T)$, and $K_{7}=23.42 \times \exp (-339 / T)$. The concentration of the third body is represented by $C_{\mathrm{M}}$. The rate constants for reactions 5 and 8 are calculated using the formula given in [27, 28].

The reaction rates for the global steps $w_{k}$, expressed in terms of the reaction rates of elementary reactions $w_{n}$, are $w_{I}=w_{7 \mathrm{f}}-w_{7 \mathrm{~b}}-w_{8}, w_{I I}=$ $w_{6 \mathrm{f}}-w_{6 \mathrm{~b}}, w_{I I I}=w_{5}+w_{8}, w_{I V}=w_{1 \mathrm{f}}-w_{1 \mathrm{~b}}$. Following the previous analysis of [13], the approximations $X_{\mathrm{OH}}=X_{\mathrm{H}_{2} \mathrm{O}} X_{\mathrm{H}} /\left(K_{3} X_{\mathrm{H}_{2}}\right)$, and $X_{\mathrm{O}}=$ 
$X_{\mathrm{H}_{2} \mathrm{O}} X_{\mathrm{H}}{ }^{2} /\left(K_{2} K_{3} X_{\mathrm{H}_{2}}{ }^{2}\right)$ are introduced, where $K_{2}=2.25 \times \exp (-782 / T)$, and $K_{3}=0.22 \times \exp (7420 / T)$.

\section{Analysis of the Structure of the Reaction Zone}

The describing equations of the structure of the reaction zone are similar to those shown in detail in $[13,17]$. Therefore a concise description is given here, highlighting the differences between the present formulation and those in $[13,17]$. For convenience, the definitions

$$
x_{\mathrm{i}} \equiv X_{\mathrm{i}} / L e_{\mathrm{i}}, \quad \omega_{\mathrm{k}} \equiv W_{\mathrm{N}_{2}}{ }^{2} w_{\mathrm{k}} / \rho^{2}, \quad Q_{\mathrm{k}} \equiv\left(-\Delta H_{\mathrm{k}}\right) / Q_{\mathrm{F}}
$$

are introduced, where $\left(-\Delta H_{\mathrm{k}}\right)$ is the heat release in the overall step $k$ of the reduced mechanism. The heats of formation at $298 \mathrm{~K}$ are, $\mathrm{CH}_{4}$ : $-75 \mathrm{~kJ} / \mathrm{mol}, \mathrm{CO}:-111 \mathrm{~kJ} / \mathrm{mol}, \mathrm{CO}_{2}$ : $-394 \mathrm{~kJ} / \mathrm{mol}, \mathrm{H}_{2} \mathrm{O}:-242 \mathrm{~kJ} / \mathrm{mol}, \mathrm{H}$ : $218 \mathrm{~kJ} / \mathrm{mol}$. Thus $\left(-\Delta H_{\mathrm{I}}\right)=-230 \mathrm{~kJ},\left(-\Delta H_{\mathrm{II}}\right)=-41 \mathrm{~kJ},\left(-\Delta H_{\mathrm{III}}\right)=$ $-436 \mathrm{~kJ},\left(-\Delta H_{\mathrm{IV}}\right)=-48 \mathrm{~kJ}$. Thus $Q_{\mathrm{I}}=0.287, Q_{\mathrm{II}}=0.052, Q_{\mathrm{III}}=0.543$, $Q_{\mathrm{IV}}=0.059$. From the definition of $Q_{\mathrm{k}}$ it follows that $Q_{\mathrm{I}}+Q_{\mathrm{II}}+Q_{\mathrm{III}}+2 Q_{\mathrm{IV}}=$ 1.

Seven reactive species appear in the four-step reduced mechanism. Since there are three chemical elements in these reactive species, four independent species balance equations can be written. The independent differential balance equations selected are those for the fuel $\left(\mathrm{CH}_{4}\right)$, H-radicals, $\mathrm{CO}$, and $\mathrm{O}_{2}$. Introducing the definition $\mathcal{L}=\left[\chi W_{\mathrm{N}_{2}} /(2 \rho)\right] d^{2} / d \xi^{2}$, the species balance equations are,

$$
\begin{aligned}
& \mathcal{L}\left(x_{\mathrm{F}}\right)=\omega_{\mathrm{I}}, \quad \mathcal{L}\left(x_{\mathrm{H}}\right)=2 \omega_{\mathrm{I}}+2 \omega_{\mathrm{III}}-2 \omega_{\mathrm{IV}} \\
& \mathcal{L}\left(x_{\mathrm{CO}}\right)=-\omega_{\mathrm{I}}+\omega_{\mathrm{II}}, \quad \mathcal{L}\left(x_{\mathrm{O}_{2}}\right)=\omega_{\mathrm{IV}}
\end{aligned}
$$


Coupling relations satisfying the conservation of chemical elements and energy can be written as

$$
\begin{aligned}
\mathcal{L}\left(4 x_{\mathrm{F}}+x_{\mathrm{H}} / 2+x_{\mathrm{CO}}+x_{\mathrm{H}_{2}}-2 x_{\mathrm{O}_{2}}\right) & =0, \\
\mathcal{L}\left(x_{\mathrm{CO}_{2}}+x_{\mathrm{F}}+x_{\mathrm{CO}}\right) & =0, \\
\mathcal{L}\left(x_{\mathrm{H}_{2} \mathrm{O}}+2 x_{\mathrm{F}}+x_{\mathrm{H}} / 2+x_{\mathrm{H}_{2}}\right) & =0, \\
\mathcal{L}\left(\tau+q_{F} x_{\mathrm{F}}+q_{\mathrm{H}} x_{\mathrm{H}}+q_{C O} x_{\mathrm{CO}}+q_{\mathrm{O}_{2}} x_{\mathrm{O}_{2}}\right) & =0,
\end{aligned}
$$

where $q_{F}=\left(Q_{\mathrm{I}}+Q_{\mathrm{II}}-Q_{\mathrm{III}}\right)=-0.204, q_{H}=Q_{\mathrm{III}} / 2=0.2715, q_{C O}=Q_{\mathrm{II}}=$ 0.543 , and $q_{O_{2}}=\left(Q_{\mathrm{III}}+Q_{\mathrm{IV}}\right)=0.602$.

Figure 6 is schematic illustration of the reaction zone structure. Profile

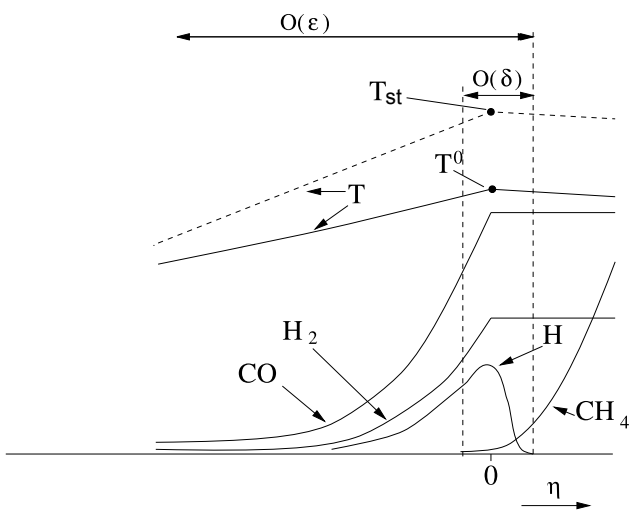

Figure 6: Schematic illustration of the reaction zone structure around $\xi_{\text {st }}$. The figure shows the inner layer and the oxidation layer.

of temperature and profiles of $\mathrm{CH}_{4}, \mathrm{O}_{2}, \mathrm{H}_{2}, \mathrm{CO}$, and $\mathrm{H}$ are shown. The temperature profiles shown by the dashed lines in Fig. 6 is a projection from the outer structure shown in Fig. 5 into the reaction zone. The global reactions of the reduced four-step mechanism take place in various layers within the reaction zone. Following previous analysis $[8,13,17]$, the reaction zone 
is presumed to be made up of an inner layer of thickness of the order of $\delta$ and an oxidation layer of thickness of the order of $\epsilon$. The ordering $\delta \ll \epsilon \ll 1$ is employed in the analysis. Figure 6 shows the relative location of inner layer and the oxidation layer in terms of the stretched coordinate $\eta$, which is used as the independent variable in the analysis of the oxidation layer. The stretched coordinate is so defined that the inner layer is located around $\eta=0$. The quantity $T^{0}$ is the peak temperature at the inner layer.

In the inner layer the global steps I and IV are active. Methane is completely consumed there, and the intermediate species $\mathrm{H}_{2}$ and $\mathrm{CO}$ are formed. The temperature at the inner layer, $T^{0}$, will be obtained from the results of the analysis. In the oxidation layer the global steps, II, III, and IV, take place. Here $\mathrm{O}_{2}$, added $\mathrm{CO}$, and $\mathrm{CO}$ and $\mathrm{H}_{2}$ produced in the inner layer, are oxidized to form $\mathrm{CO}_{2}$ and $\mathrm{H}_{2} \mathrm{O}$. The global step I is inactive in the oxidation layer because the value of $X_{\mathrm{F}}$ is very small. Oxygen is consumed primarily in the oxidation layer. It is noteworthy that consumption of $\mathrm{CO}$ primarily takes place in the oxidation layer irrespective of the reactant stream to which it is added. As a consequence, the analyses of the inner layer in $[13,17]$ are applicable here. The oxidation layer is analyzed first.

\subsection{The Oxidation Layer}

In the oxidation layer the concentration of fuel is negligibly small, therefore the influence of the global step I is neglected. Steady-state approximation is introduced for H. It follows from Eq. (11) that $\omega_{\text {III }}=\omega_{\text {IV }}$. Using Eq. (10), the result

$$
X_{\mathrm{H}}=K_{1}{ }^{1 / 2} K_{2}{ }^{1 / 2} K_{3} X_{\mathrm{H}_{2}}{ }^{3 / 2} X_{\mathrm{O}_{2}}{ }^{1 / 2}\left(1-k_{5} C_{\mathrm{M}} / k_{1 \mathrm{f}}\right)^{1 / 2} / X_{\mathrm{H}_{2} \mathrm{O}},
$$


is obtained. These approximations reduce the four-step mechanism to a twostep mechanism

$$
\begin{array}{lll}
\mathrm{CO}+\mathrm{H}_{2} \mathrm{O} & \rightleftharpoons \mathrm{CO}_{2}+\mathrm{H}_{2}, & \text { II } \\
\mathrm{O}_{2}+2 \mathrm{H}_{2} & \rightleftharpoons 2 \mathrm{H}_{2} \mathrm{O} . & \text { III }^{\prime}
\end{array}
$$

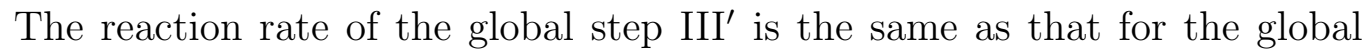
step III of the four-step mechanism. There are now five reactive species in the global steps II and III' and three elements. Therefore, two independent species balance equation can be written. The differential equations for CO and $\mathrm{O}_{2}$ are selected for describing the structure of oxidation layer. These equations obtained from Eq. (10), (11), and (13) are,

$$
\begin{aligned}
& d^{2} x_{\mathrm{CO}} / d \xi^{2}=D_{\mathrm{III}} M C \bar{S} G_{\mathrm{II}} x_{\mathrm{O}_{2}}{ }^{1 / 2} x_{\mathrm{H}_{2}}{ }^{1 / 2}\left(x_{\mathrm{CO}}-\alpha G_{\mathrm{a}} x_{\mathrm{H}_{2}}\right) /\left(2^{1 / 2} g\right) . \\
& d^{2} x_{\mathrm{O}_{2}} / d \xi^{2}=D_{\mathrm{III}} M C G_{\mathrm{III}} x_{\mathrm{O}_{2}}{ }^{3 / 2} x_{\mathrm{H}_{2}}{ }^{3 / 2} /\left(2^{3 / 2} g^{2}\right) .
\end{aligned}
$$

Here

$$
\begin{aligned}
& D_{\mathrm{III}} \equiv 2^{5 / 2} \rho^{0} g^{2} k_{5}^{0} C_{\mathrm{M}}^{0}\left[K_{1}^{0} K_{2}^{0} K_{3}^{0^{2}}\right]^{1 / 2} L e_{\mathrm{H}_{2}}{ }^{3 / 2} L e_{\mathrm{O}_{2}}{ }^{3 / 2}(1-\kappa)^{1 / 2} /\left(\chi^{0} X_{\mathrm{H}_{2} \mathrm{O}, \mathrm{st}} W_{\mathrm{N}_{2}}\right) \\
& \bar{S} \equiv k_{6 \mathrm{f}}^{0} L e_{\mathrm{CO}} X_{\mathrm{H}_{2} \mathrm{O}, \mathrm{st}} /\left(2 k_{5}^{0} C_{\mathrm{M}}^{0} K_{3}^{0} g L e_{\mathrm{H}_{2}} L e_{\mathrm{O}_{2}}\right) \\
& \alpha \equiv K_{3}^{0} X_{\mathrm{CO}_{2}, \mathrm{st}} L e_{\mathrm{H}_{2}} /\left(K_{6}^{0} X_{\mathrm{H}_{2} \mathrm{O}, \mathrm{st}} L e_{\mathrm{CO}}\right), \quad \kappa \equiv k_{5}^{0} C_{\mathrm{M}}^{0} / k_{1 \mathrm{f}}^{0} .
\end{aligned}
$$

Here $k_{\mathrm{n}}^{0}$ and $K_{\mathrm{n}}^{0}$ are, respectively, the reaction rate coefficients and equilibrium constants of the elementary reaction $\mathrm{n}$ evaluated at $T=T^{0}$. The quantity $\chi^{0}$ is the scalar dissipation rate, evaluated at the inner layer. The 
quantities $G_{\mathrm{II}}, G_{\mathrm{III}}, G_{\mathrm{a}}, G_{\mathrm{b}}, M$, and $C$ are defined as

$$
\begin{aligned}
& G_{\mathrm{II}}=\rho k_{6 \mathrm{f}} K_{1}{ }^{1 / 2} K_{2}{ }^{1 / 2} /\left(\rho^{0} k_{6 \mathrm{f}}^{0} K_{1}^{01 / 2} K_{2}^{01 / 2}\right)=\exp \left[-m_{\mathrm{II}}\left(1 / T-1 / T^{0}\right)\right], \\
& G_{\mathrm{III}}=\rho k_{5} C_{\mathrm{M}} K_{1}{ }^{1 / 2} K_{2}{ }^{1 / 2} K_{3} /\left(\rho^{0} k_{5}^{0} C_{\mathrm{M}}^{0} K_{1}^{01 / 2} K_{2}^{01 / 2} K_{3}^{0}\right)=\exp \left[-m_{\mathrm{III}}\left(1 / T-1 / T^{0}\right)\right], \\
& G_{\mathrm{a}}=K_{3} K_{6}^{0} /\left(K_{3}^{0} K_{6}\right)=\exp \left[-m_{\mathrm{a}}\left(1 / T-1 / T^{0}\right)\right], \\
& G_{\mathrm{b}}=k_{1 \mathrm{f}}^{0} k_{5} C_{\mathrm{M}} /\left(k_{1 \mathrm{f}} k_{5}^{0} C_{\mathrm{M}}^{0}\right)=\exp \left[-m_{\mathrm{b}}\left(1 / T-1 / T^{0}\right)\right], \\
& M=\left(1-G_{\mathrm{b}} \kappa\right)^{1 / 2} /(1-\kappa)^{1 / 2}, \quad C=\chi^{0} / \chi
\end{aligned}
$$

The quantities $m_{\mathrm{II}}, m_{\mathrm{III}}, m_{\mathrm{a}}$, and $m_{\mathrm{b}}$ represent the effective activation temperature. They are evaluated from the rate data shown in Table 1. The contribution of the temperature exponent of the rate constant, $\alpha_{n}$, is estimated employing the approximation $T^{\alpha_{n}}=T_{m}^{\alpha_{n}} \exp \left(\alpha_{n}\right) \exp \left(-\alpha_{n} T_{m} / T\right)$ [8]. Here $T_{m}$ is a reference temperature. For $T_{m}=1600 \mathrm{~K}$, using the rate data in Table (1), the values $m_{\mathrm{II}}=4800 \mathrm{~K}, m_{\mathrm{III}}=-7847 \mathrm{~K}, m_{\mathrm{a}}=3903 \mathrm{~K}$, and $m_{\mathrm{b}}=-11790 \mathrm{~K}$ are obtained [17].

The profiles for $\mathrm{H}_{2}, \mathrm{CO}_{2}, \mathrm{H}_{2} \mathrm{O}$ and the temperature in the oxidation layer can be obtained from the coupling relations shown in Eq. (12). These coupling relations are

$$
\begin{aligned}
& d^{2}\left(x_{\mathrm{CO}}+x_{\mathrm{H}_{2}}-2 x_{\mathrm{O}_{2}}\right) / d \xi^{2}=0, \quad d^{2}\left(x_{\mathrm{CO}_{2}}+x_{\mathrm{CO}}\right) / d \xi^{2}=0, \\
& d^{2}\left(x_{\mathrm{H}_{2} \mathrm{O}}+x_{\mathrm{H}_{2}}\right) / d \xi^{2}=0, \quad d^{2}\left(\tau+q_{C O} x_{\mathrm{CO}}+q_{\mathrm{O}_{2}} x_{\mathrm{O}_{2}}\right) / d \xi^{2}=0 .
\end{aligned}
$$

To analyze the structure of the oxidation layer the expansions

$$
\begin{aligned}
& \xi-\xi_{\mathrm{st}}=\epsilon\left(\eta+\eta^{0}\right), \quad x_{\mathrm{O}_{2}}=\epsilon g\left[z_{\mathrm{O}_{2}}-2 b\left(\eta+\eta^{0}\right) / g\right], \\
& x_{\mathrm{H}_{2}}=\epsilon 2 g z_{\mathrm{H}_{2}}, \quad x_{\mathrm{CO}}=\epsilon 2 g\left[z_{\mathrm{CO}}-n\left(\eta+\eta^{0}\right) /(2 g)\right], \\
& \tau=\tau_{\mathrm{st}}-\epsilon\left[2 g q_{C O} z_{\mathrm{CO}}+g q_{\mathrm{O}_{2}} z_{\mathrm{O}_{2}}-s\left(\eta+\eta^{0}\right)\right],
\end{aligned}
$$


are introduced, where $\epsilon$ is small and the variables $\eta^{0}, z_{\mathrm{O}_{2}}, z_{\mathrm{CO}}$ and $z_{\mathrm{H}_{2}}$ are presumed to be of the order of unity. Here $\xi_{\text {st }}+\epsilon \eta^{0}$ gives the location of the inner layer. Matching the profiles of $\mathrm{O}_{2}$ and $\mathrm{CO}$ in the oxidation layer with those in the outer structure in the region $\xi<\xi_{\text {st }}$ given by Eq. (9), the results

$$
d z_{\mathrm{CO}} / d \eta=d z_{\mathrm{O}_{2}} / d \eta=0 \text { as } \eta \rightarrow-\infty .
$$

are obtained. The expansion for $\tau$ is so written that it satisfies the coupling relations Eq. (17) and $z_{\mathrm{H}_{2}}=z_{\mathrm{O}_{2}}-z_{\mathrm{CO}}$.

The small expansion parameter $\epsilon$ is so chosen that it can be calculated from the equation

$$
\epsilon=\left(D_{\mathrm{III}}\right)^{-1 / 4} .
$$

Introducing into Eqs. (14), the expansions given by Eq. (18), the definition of $\epsilon$ in Eq. (20), and $S=\bar{S} / \epsilon$, the following equations are obtained for $z_{\mathrm{CO}}$ and $z_{\mathrm{H}_{2}}$

$$
\begin{aligned}
d^{2} z_{\mathrm{CO}} / d \eta^{2}= & G_{\mathrm{II}} S C M{z_{\mathrm{H}_{2}}}^{1 / 2}\left[z_{\mathrm{O}_{2}}-2 b\left(\eta+\eta^{0}\right) / g\right]^{1 / 2} \times \\
& {\left[z_{\mathrm{CO}}-n\left(\eta+\eta^{0}\right) /(2 g)-\alpha G_{\mathrm{a}} z_{\mathrm{H}_{2}}\right], } \\
d^{2} z_{\mathrm{O}_{2}} / d \eta^{2}= & G_{\mathrm{III}} C M{z_{\mathrm{H}_{2}}}^{3 / 2}\left[z_{\mathrm{O}_{2}}-2 b\left(\eta+\eta^{0}\right) / g\right]^{3 / 2} .
\end{aligned}
$$

Here the quantity $C=\exp \left[-2 \epsilon \eta /\left(\xi_{\text {st }}+\epsilon \eta^{0}\right)\right]$ includes changes in the values of $\chi$ with $\eta$ in the oxidation layer. In view of Eqs. (2) and (18), $T=T_{\mathrm{st}}-$ $\epsilon Q_{\mathrm{F}}\left[2 g q_{C O} z_{\mathrm{CO}}+g q_{\mathrm{O}_{2}} z_{\mathrm{O}_{2}}-s\left(\eta+\eta^{0}\right)\right] /\left(c_{\mathrm{p}} W_{\mathrm{N}_{2}}\right)$. At $\eta=0$, the values of $T$, $z_{\mathrm{CO}}, z_{\mathrm{H}_{2}}$, and $z_{\mathrm{O}_{2}}$ are $T^{0}, z_{\mathrm{CO}}^{0}, z_{\mathrm{H}_{2}}^{0}, z_{\mathrm{O}_{2}}^{0}$ respectively. Hence,

$$
T=T^{0}-\epsilon Q_{\mathrm{F}}\left[2 g q_{C O}\left(z_{\mathrm{CO}}-z_{\mathrm{CO}}^{0}\right)+g q_{\mathrm{O}_{2}}\left(z_{\mathrm{O}_{2}}-z_{\mathrm{O}_{2}}^{0}\right)-s \eta\right] /\left(W_{\mathrm{N}_{2}} c_{\mathrm{p}}\right),
$$

and an alternate expression for $\epsilon$ is

$$
\epsilon=c_{\mathrm{p}} W_{\mathrm{N}_{2}}\left(T_{\mathrm{st}}-T^{0}\right)\left[Q_{\mathrm{F}}\left(2 g q_{C O} z_{\mathrm{CO}}^{0}+g q_{\mathrm{O}_{2}} z_{\mathrm{O}_{2}}^{0}-s \eta^{0}\right)\right]^{-1} .
$$


It follows from Eq. (22) that the leading order expansion for $1 / T$ is

$$
1 / T-1 / T^{0}=\epsilon Q_{\mathrm{F}}\left[2 g q_{C O}\left(z_{\mathrm{CO}}-z_{\mathrm{CO}}^{0}\right)+g q_{O_{2}}\left(z_{\mathrm{O}_{2}}-z_{\mathrm{O}_{2}}^{0}\right)-s \eta\right] /\left(c_{\mathrm{p}} W_{\mathrm{N}_{2}} T^{0^{2}}\right) .
$$

The values of $G_{\mathrm{II}}, G_{\mathrm{III}}, G_{\mathrm{a}}$, and $G_{\mathrm{b}}$ defined in Eq. (16) are evaluated using Eq. (24).

Boundary conditions for Eq. (21) at $\eta=0$ are obtained by considering the jump conditions across the inner layer. In the inner layer, if the influence of the global steps II and III on the structure of this layer is neglected, then the coupling relations

$$
\begin{aligned}
& d^{2}\left(x_{\mathrm{F}}+x_{\mathrm{CO}}\right) / d \xi^{2}=0, \quad d^{2}\left(x_{\mathrm{F}}+3 x_{\mathrm{H}} / 2+x_{\mathrm{H}_{2}}\right) / d \xi^{2}=0 \\
& d^{2}\left(x_{\mathrm{O}_{2}}+x_{\mathrm{H}} / 2+x_{\mathrm{F}}\right) / d \xi^{2}=0
\end{aligned}
$$

are obtained. Integrating Eq. (25) once and matching the slopes with those given by Eq. (8) gives the result $d\left(x_{\mathrm{F}}+x_{\mathrm{CO}}\right) / d \xi=g+m, d\left(x_{\mathrm{F}}+3 x_{\mathrm{H}} / 2+\right.$ $\left.x_{\mathrm{H}_{2}}\right) / d \xi=g$, and $d\left(x_{\mathrm{O}_{2}}+x_{\mathrm{H}} / 2-x_{\mathrm{F}}\right) / d \xi=-g$. Using the expansions given by Eq. (18), the boundary conditions

$$
\begin{aligned}
& d z_{\mathrm{CO}} / d \eta=1 / 2+n /(2 g)+m /(2 g)=1 / 2+2 r, \\
& d z_{\mathrm{O}_{2}} / d \eta=2 b / g-1=1+2 r
\end{aligned}
$$

are obtained at $\eta=0$. Profiles of $z_{\mathrm{CO}}$ and $z_{\mathrm{O}_{2}}$ and are obtained as functions of $\eta$ from numerical integration of Eq. (21). The values of $z_{\mathrm{O}_{2}}^{0}$, and $z_{\mathrm{H}_{2}}^{0}=$ $z_{\mathrm{O}_{2}}^{0}-z_{\mathrm{CO}}^{0}$ obtained from these profiles are used to evaluate $X_{\mathrm{O}_{2}}^{0}$ and $X_{\mathrm{H}_{2}}^{0}$ from

$$
X_{\mathrm{O}_{2}}^{0}=\epsilon g L e_{\mathrm{O}_{2}}\left(z_{\mathrm{O}_{2}}^{0}-2 b \eta^{0} / g\right), X_{\mathrm{H}_{2}}^{0}=\epsilon 2 g L e_{\mathrm{H}_{2}} z_{\mathrm{H}_{2}}^{0} .
$$

They are used in the analysis of the inner layer. 


\subsection{The Inner Layer}

The analysis of the inner layer is similar to that described elsewhere [17], therefore only the results are shown. The thickness of the inner layer, $\delta$ is

$$
\delta^{2}=\frac{2^{3 / 2} g^{2} k_{5}^{0} C_{\mathrm{M}}^{0} k_{8}^{0} K_{2}^{0^{1 / 2}} L e_{\mathrm{O}_{2}}{ }^{3 / 2} L e_{\mathrm{H}_{2}}{ }^{3 / 2} \epsilon^{4}}{k_{7 \mathrm{f}}^{0} k_{9}^{0} K_{1}^{01 / 2} L e_{\mathrm{F}} X_{\mathrm{O}_{2}}^{0} X_{\mathrm{H}_{2}}^{0}}(1-\kappa)^{1 / 2} .
$$

The structure of the inner layer is obtained from numerical integration of two coupled second-order differential equations, one for $\mathrm{CH}_{4}$ and the other for $\mathrm{H}$. These equations are shown elsewhere [13] and they include an eigenvalue $\omega$ given by

$$
\omega^{2}=\frac{2^{7 / 2} g^{4} \epsilon^{4} k_{5}^{0} C_{\mathrm{M}}^{0} k_{8}^{0^{3}} K_{2}^{0^{1 / 2}} X_{\mathrm{H}_{2} \mathrm{O}, \mathrm{st}}{ }^{2} L e_{\mathrm{H}}{ }^{2} L e_{\mathrm{O}_{2}}{ }^{3 / 2} L e_{\mathrm{H}_{2}}{ }^{3 / 2}}{k_{\mathrm{ff}}^{0} k_{9}^{0^{3}} K_{1}^{0^{5 / 2}} K_{3}^{0^{2}} X_{\mathrm{O}_{2}}^{0}{ }^{3} X_{\mathrm{H}_{2}}^{0} L e_{\mathrm{F}}}(1-\kappa)^{1 / 2} .
$$

The coupled differential equations for $\mathrm{CH}_{4}$ and $\mathrm{H}$ are required to satisfy five boundary conditions [13]. The equations are integrated numerically, with the additional boundary condition being used to obtain $\omega$.

\subsection{The Scalar Dissipation Rate}

The results of the asymptotic analysis are employed to predict the value of $\chi_{\mathrm{q}}^{0}$, which is the value of $\chi^{0}$ at extinction. For given values of temperature and mass fractions of the reactants at the boundaries, the outer structure can be constructed using the procedure described in section 4.1. A value of $\eta^{0}$ is selected. The goal is to predict the scalar dissipation rate, $\chi^{0}$, that is consistent with this selected value of $\eta^{0}$. An iterative procedure is employed. It begins by selecting an appropriate value of $T^{0}$. The rate constants and equilibrium constants are evaluated. A second iteration is required and it is carried out after selecting an appropriate value of $\epsilon$. This permits evaluation 
of the quantity $S$ given by Eq. (21). Equations (21) are integrated and the results are used to obtain $z_{\mathrm{O}_{2}}^{0}$, and $z_{\mathrm{H}_{2}}^{0}$. The quantity $\epsilon$ is calculated using Eq. (23) and compared with the selected value. The iteration is continued until the selected value of $\epsilon$ agrees with the calculated value. The quantities $X_{\mathrm{O}_{2}}^{0}$ and $X_{\mathrm{H}_{2}}^{0}$ are calculated using Eq. (27). The coupled differential equations for $\mathrm{CH}_{4}$, and $\mathrm{H}$ describing the structure of the inner layer are integrated and the value of $\omega$ is obtained. This is compared with $\omega$ calculated using Eq. (29). If they are not the same, the procedure is repeated with a different value of $T^{0}$ until the value of $\omega$, obtained from integration of the coupled differential equations for $\mathrm{CH}_{4}$ and $\mathrm{H}$, agrees with that calculated using Eq. (29). The value of $\chi^{0}$, that is consistent with the selected value of $\eta^{0}$, is calculated by recasting Eq. (20) as

$$
\chi^{0}=\frac{2^{5 / 2} \rho^{0} g^{2} k_{5}^{0} C_{\mathrm{M}}^{0}\left(K_{1}^{0} K_{2}^{0} K_{3}^{0^{2}}\right)^{1 / 2}(1-\kappa)^{1 / 2} L e_{\mathrm{H}_{2}}{ }^{3 / 2} L e_{\mathrm{O}_{2}}{ }^{3 / 2} \epsilon^{4}}{X_{\mathrm{H}_{2} \mathrm{O}, \mathrm{st}} W_{\mathrm{N}_{2}}} .
$$

The entire procedure is repeated with another selected value of $\eta^{0}$. The classical C-shaped curve is obtained when $T^{0}$ is plotted as a function of $\left(\chi^{0}\right)^{-1}$. The value of $\left(\chi^{0}\right)^{-1}$, where its derivative with respect to $T^{0}$ in the C-shaped curve is zero, represents the critical condition at extinction. At this critical condition, the value of $\chi^{0}$ is denoted by $\chi_{\mathrm{q}}$. Although the procedure to obtain the critical conditions of extinction is somewhat arduous, the key outcome of this work is that flame structure and critical condition of extinction can be predicted from integration of four coupled ordinary differential equations, two in the inner layer and two in the oxidation layer. 


\section{Results and Discussion}

Experimental measurements and computational predictions of strain rates of methane flames at extinction, $a_{\mathrm{e}}$, with $\mathrm{CO}$ added either to the fuel stream or to the oxidizer stream have been reported elsewhere [16]. The temperature of the reactant streams at the boundaries were maintained at $298 \mathrm{~K}$, and the pressure was $1 \mathrm{~atm}$. Two sets of experimental data were obtained. In each set the mass fractions of the reactants at the boundaries were so selected that the adiabatic temperature $T_{\text {st }}$ and the stoichiometric mixture fraction, $\xi_{\text {st }}$, are the same. In one set of experiments, $T_{\mathrm{st}}=2000 \mathrm{~K}$, and $\xi_{\mathrm{st}}=0.055$ and in the other $T_{\mathrm{st}}=2100 \mathrm{~K}$, and $\xi_{\mathrm{st}}=0.055$. At these conditions, the amounts of $\mathrm{CO}$ addition to the reactant streams were $0 \leq Y_{\mathrm{CO}, 1} \ll 0.26$ and $0 \leq Y_{\mathrm{CO}, 2} \ll 0.24$.

To predict the flame structures and critical conditions of extinction from the asymptotic analysis, the values of $C_{\mathrm{M}}^{0}, \rho^{0}$, and $c_{\mathrm{p}}$, are evaluated using the relations given in $[13,30]$. They are $C_{\mathrm{M}}^{0}=0.02027 / T^{0} \mathrm{~mol} / \mathrm{cm}^{3}, \rho^{0}=$ $0.000351 / T^{0} \mathrm{~kg} / \mathrm{cm}^{3}$, and $c_{\mathrm{p}}=1045+0.24 T-0.2 T^{2} \mathrm{~J} /(\mathrm{kg} \cdot \mathrm{K})$. The molecular weights are $W_{\mathrm{F}}=0.016 \mathrm{~kg} / \mathrm{mol}, W_{\mathrm{N}_{2}}=0.028 \mathrm{~kg} / \mathrm{mol}, W_{\mathrm{CO}}=0.028 \mathrm{~kg} / \mathrm{mol}$, $W_{\mathrm{O}_{2}}=0.032 \mathrm{~kg} / \mathrm{mol}$, and $W_{\mathrm{H}_{2}}=0.002 \mathrm{~kg} / \mathrm{mol}$, and the Lewis numbers of various species are $L e_{\mathrm{F}}=0.97, L e_{\mathrm{H}_{2}}=0.3, L e_{\mathrm{O}_{2}}=1.0, L e_{\mathrm{CO}}=1.11$, and $L e_{\mathrm{H}}=0.2[30]$.

Figures 7, 8, and 9 show predictions of changes in values of $T^{0}, X_{\mathrm{O}_{2}}^{0}$, and $\epsilon$ with changes in $\left(\chi^{0}\right)^{-1}$ for $Y_{\mathrm{CO}, 2}=0.02$. All plots in these figures show the classical "C-shaped" behavior. With decreasing values of $\left(\chi^{0}\right)^{-1}$, the flame temperature decreases, the leakage of oxygen from the reaction zone, and 

oxidizer stream, with $Y_{\mathrm{CO}, 2}=0.02$

the thickness of the oxidation layer increases. All plots show that there are no solutions for values of $\left(\chi^{0}\right)^{-1}$ below a critical value. This critical value of $\left(\chi^{0}\right)^{-1}$ is the scalar dissipation rate at extinction.

The experimental results of [16] give the strain rates at extinction, while the asymptotic analysis give the scalar dissipation rate at extinction. It has been shown that the scalar dissipation rate at extinction is directly proportional to the strain rate at extinction, and the constant of proportionality depends of $T_{\text {st }}$ and $\xi_{\text {st }}[20]$. Hence at fixed $\xi_{\text {st }}$ and $T_{\text {st }}$ the ratio $a_{\mathrm{e}} / a_{\mathrm{e}, 0}=\chi_{\mathrm{q}} / \chi_{\mathrm{q}, 0}$, where $a_{\mathrm{e}, 0}$ and $\chi_{\mathrm{q}, 0}$ are the strain rate and scalar dissipation rate at extinction for $Y_{\mathrm{CO}, 2}=Y_{\mathrm{CO}, 1}=0$. For $T_{\mathrm{st}}=2000 \mathrm{~K}$, and $\xi_{\mathrm{st}}=0.055$ the value of the scalar dissipation rate at extinction, $\chi_{\mathbf{q}, 0}$, calculated using the formula in [20] and the experimentally measured value of $a_{\mathrm{e}}$ is $10.1 \mathrm{~s}^{-1}$, while the predicted 


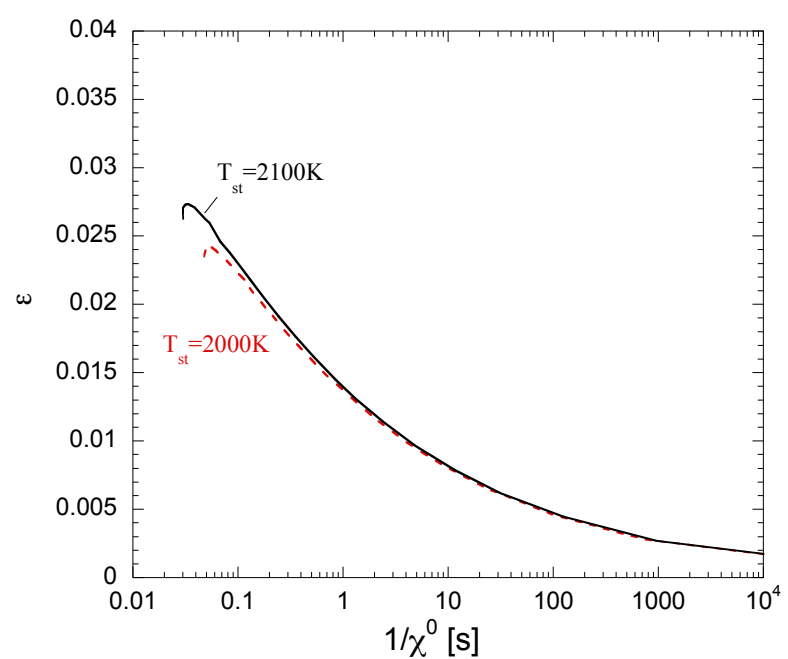

Figure 9: The characteristic thickness of the oxidation layer, $\epsilon$, as a function of $\left(\chi^{0}\right)^{-1}$, for $\mathrm{CO}$ addition to the oxidizer stream, with $Y_{\mathrm{CO}, 2}=0.02$ 
value, using the results of RRA, is $16.3 \mathrm{~s}^{-1}$. The differences between the measured and predicted value of $\chi_{\mathrm{q}}$ is attributed to inaccuracies in calculating $\chi_{\mathrm{q}}$ employing the formula in [20]. In view of these inaccuracies, comparisons of predicted values of the ratio $\chi_{\mathrm{q}} / \chi_{\mathrm{q}, 0}$ with the measured values of $a_{\mathrm{e}} / a_{\mathrm{e}, 0}$, is more indicative of the accuracy with which the asymptotic analysis captures the influence of $\mathrm{CO}$ on flame structure than with comparisons of absolute values. The ratios help to remove the inaccuracies that are present in predictions of critical conditions of extinction of methane flames without added carbon monoxide.

Figures 10 and 11 show the ratio $\chi_{\mathrm{q}} / \chi_{\mathrm{q}, 0}$ as a function of the mass fraction of $\mathrm{CO}$ added to the oxidizer stream, $Y_{\mathrm{CO}, 2}$, and $\mathrm{CO}$ added to the fuel stream, $Y_{\mathrm{CO}, 1}$. The lines are predictions of the asymptotic analysis, the broken lines are computational predictions obtained using the San Diego Mechanism [16], and the symbols represent experimental data [16]. The computational predictions and experimental data are ratios of strain rates, $a_{\mathrm{e}} / a_{\mathrm{e}, 0}$. Figure 10 shows results at fixed $T_{\mathrm{st}}=2000 \mathrm{~K}$ and $\xi_{\mathrm{st}}=0.055$ and Fig. 11 at fixed $T_{\text {st }}=2100 \mathrm{~K}$ and $\xi_{\text {st }}=0.055$. Both figures show that the qualitative agreement between the predictions of the asymptotic analysis and computational predictions using detailed chemistry and measurements are good. The quantitative agreement for $\mathrm{CO}$ addition to the fuel stream is good. For CO addition to the oxidizer stream, the asymptotic predictions agree with measurements for small values of $Y_{\mathrm{CO}, 2}$ while at higher values of $Y_{\mathrm{CO}, 2}$ the predicted value of $\chi_{\mathrm{q}} / \chi_{\mathrm{q}, 0}$ from asymptotic analysis is lower than the measurements and computations. 


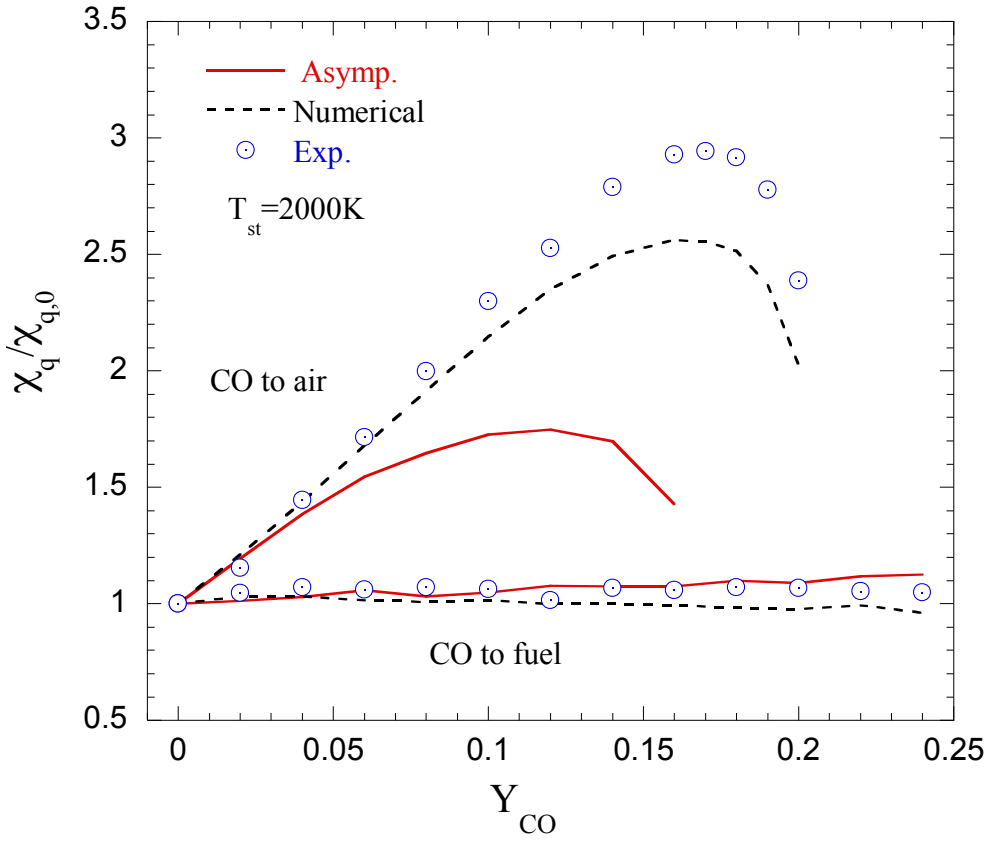

Figure 10: The ratio $\chi_{\mathrm{q}} / \chi_{\mathrm{q}, 0}$ at extinction for various values of $\mathrm{CO}$ added either to the oxidizer stream, or to the fuel stream, at fixed $T_{\mathrm{st}}=2000 \mathrm{~K}$, and $\xi_{\mathrm{st}}=0.055$. The lines are predictions of the asymptotic analysis, the broken lines are computational predictions obtained using the San Diego Mechanism [16] and the symbols are measurements [16]. 


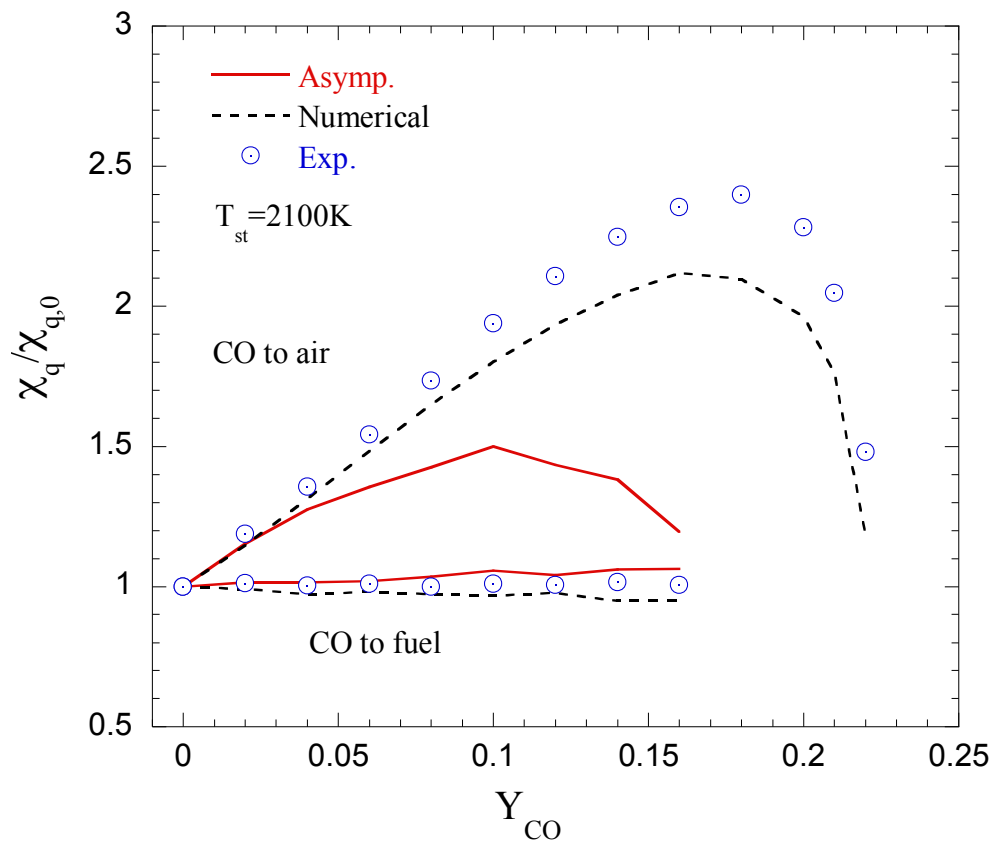

Figure 11: The ratio $\chi_{\mathrm{q}} / \chi_{\mathrm{q}, 0}$ at extinction for various values of $\mathrm{CO}$ added either to the oxidizer stream, or to the fuel stream, at fixed $T_{\mathrm{st}}=2100 \mathrm{~K}$, and $\xi_{\mathrm{st}}=0.055$. The lines are predictions of the asymptotic analysis, the broken lines are computational predictions obtained using the San Diego Mechanism [16] and the symbols are measurements [16]. 
Figures 12, 13, 14, 15 and 16 show predicted values of various quantities as function of $r$ defined in Eq. (4). The symbols in these figures are for CO addition to the fuel stream and the lines for $\mathrm{CO}$ addition to the oxidizer stream. For CO addition to the fuel stream the range of values of $r$ is very small, less than 0.05 , in comparison to that for $\mathrm{CO}$ addition to the oxidizer stream where the value can be as high as 10 . Plotting results as functions of $r$ allows aspects of the structure of the oxidation layer for $\mathrm{CO}$ addition to the fuel stream and to the oxidizer stream to be shown together in a single plot. In Fig. 11 the range of values of $r$ for $\mathrm{CO}$ addition to the oxidizer stream is 0 to 1.0, while for $\mathrm{CO}$ addition to the fuel stream it is 0 to 0.05 .

Figure 12 and 13, respectively, show the values of $z_{\mathrm{O}_{2}}^{0}$ and $z_{\mathrm{CO}}^{0}$, obtained from numerical integration of Eq. (21). Figures 12 and 13 show that the increase in the values of $z_{\mathrm{O}_{2}}^{0}$ and $z_{\mathrm{CO}}^{0}$ is small for $\mathrm{CO}$ addition to the fuel stream but are significant for $\mathrm{CO}$ addition to the oxidizer stream. As a consequence the leakage of $\mathrm{O}_{2}$ and $\mathrm{CO}$ from the reaction zone, characterized by the values of $X_{\mathrm{O}_{2}}^{0}$, and $X_{\mathrm{CO}}^{0}$, increase with increasing $r$. Therefore, the approximation employed in the analysis of reaction zone, that concentrations of $\mathrm{O}_{2}$ and $\mathrm{CO}$ are of the order of $\epsilon$, is expected to be valid for $\mathrm{CO}$ addition to the fuel stream and only for small values of $r$ for $\mathrm{CO}$ addition to the oxidizer stream. This result is consistent with the predictions obtained using detailed mechanism shown in Figs. 1, 2, and 3 that show that leakages of $\mathrm{O}_{2}$ and $\mathrm{CO}$ to increase with increasing values of $Y_{\mathrm{CO}, 2}$. This is the main reason for the differences between predictions and measurements shown in Figs. 10 and 11 
Figure 12: The value of $z_{\mathrm{O}_{2}}^{0}$ at extinction obtained from numerical integration of Eq. (21) as a function of $r$. The symbols are for $\mathrm{CO}$ addition to the fuel stream and the lines for $\mathrm{CO}$ addition to the oxidizer stream.

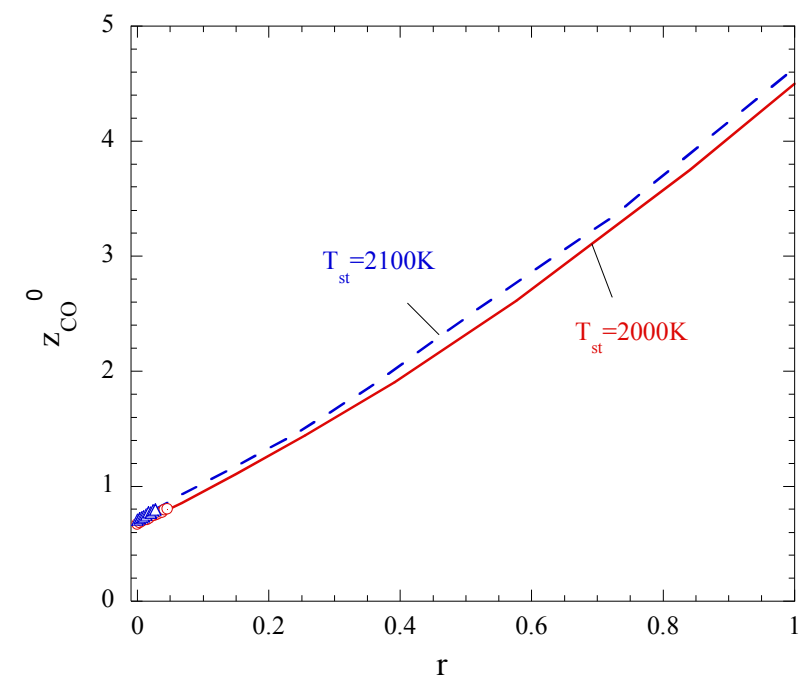

Figure 13: The value of $z_{\mathrm{CO}}^{0}$ at extinction obtained from numerical integration of Eq. (21) as a function of $r$. The symbols are for $\mathrm{CO}$ addition to the fuel stream and the lines for $\mathrm{CO}$ addition to the oxidizer stream. 


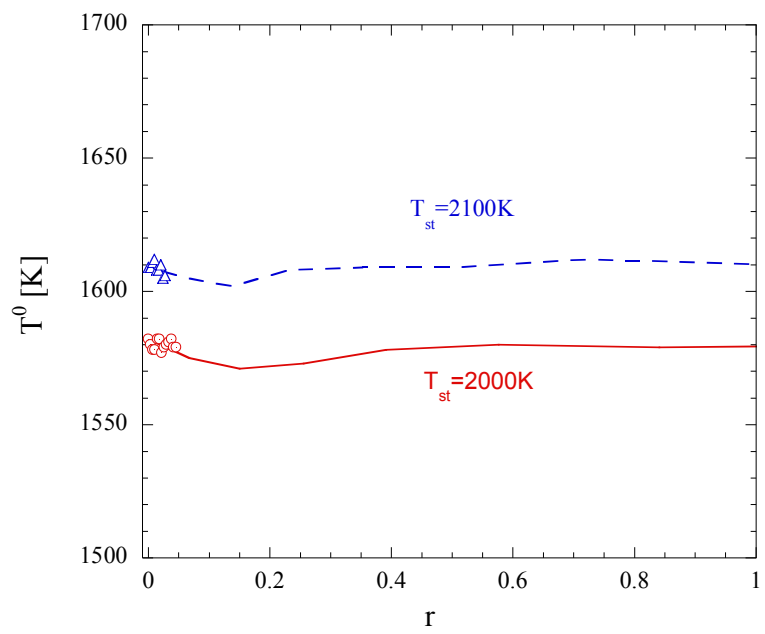

Figure 14: The value of the temperature at the inner layer at extinction, $T^{0}$ as a function of $r$. The symbols are for $\mathrm{CO}$ addition to the fuel stream and the lines for $\mathrm{CO}$ addition to the oxidizer stream.

for $\mathrm{CO}$ addition to the oxidizer stream.

Figure 14 and 15, respectively, show the values of the temperature at the inner layer, $T^{0}$, and its location, $\eta^{0}$, as a function of $r$. Figure 14 shows that there is very little change in the value of $T^{0}$. This confirms the early predictions of Peters and Williams [1], that $T^{0}$ is a kinetic property of the chemical system. Figure 15 shows that with increasing $r$ the value of $\eta^{0}$ increases. The inner layer is located at $\xi_{\text {st }}+\epsilon \eta^{0}$ as shown by Eq. (18). Therefore with addition of $\mathrm{CO}$ either to the fuel stream or to the oxidizer stream the flame moves toward the injection plane of the fuel stream and away from the injection plane of the oxidizer stream. The movement is small for $\mathrm{CO}$ addition to the fuel stream and significant for $\mathrm{CO}$ addition to the oxidizer stream. These results are again consistent with computational predictions shown in 
Figure 15: The predicted location of the inner layer at extinction, $\eta^{0}$, as a function of $r$. The symbols are for $\mathrm{CO}$ addition to the fuel stream and the lines for $\mathrm{CO}$ addition to the oxidizer stream.

Figs. 1, 2, and 3. Recently an analytical, computational and experimental study was carried out to characterize the influence of stoichiometric mixture fraction on critical conditions of extinction of nonpremixed methane flames [31]. It was found that at fixed adiabatic temperature increasing the value of the stoichiometric mixture fraction increases the scalar dissipation rate at extinction. In view of this previous finding, the increase in the value of the $\chi_{\mathrm{q}} / \chi_{\mathrm{q}, 0}$ with increasing $Y_{\mathrm{CO}, 2}$ is likely from increase in value of $\eta^{0}$. In this previous work [31], the changes in the value of $\xi_{\text {st }}$ was to the leading order, while in the present analysis it is to the first order. It is noteworthy that this finding is different from that observed in a previous RRA investigation of $\mathrm{H}_{2}$ addition to the reactant streams of methane flames [17], where it was found that with increasing $r$ (defined for $\mathrm{H}_{2}$ addition to reactant streams similar to that in Eq. (4)) the value of $\eta^{0}$ increases slightly for hydrogen addition to 
Figure 16: Predicted value of $\delta$ and $\epsilon$ at extinction as a function of $r$. The symbols are for $\mathrm{CO}$ addition to the fuel stream and the lines for $\mathrm{CO}$ addition to the oxidizer stream.

the oxidizer stream, while there is significant increase in the value of $\eta^{0}$ when $\mathrm{H}_{2}$ is added to the fuel stream. The differences can clearly be attributed to higher reactivity of $\mathrm{H}_{2}$ with respect to $\mathrm{CH}_{4}$, in contrast to the lower reactivity of $\mathrm{CO}$ with respect to $\mathrm{CH}_{4}$.

Figure 16 shows the value of the thickness of the inner layer, $\delta$ and the thickness of oxidation layer, $\epsilon$ as a function of $r$. For all $r$ the value of $\delta$ is less than that of $\epsilon$, and both are less than unity. This confirms the ordering $\delta \ll \epsilon \ll 1$ employed in the analysis.

Figures 12, 13, 14, 15 and 16 show that the structure of the oxidation layer of reaction zones with $\mathrm{CO}$ added to the fuel stream is similar to that with $\mathrm{CO}$ added to the oxidizer stream when plotted as a function of $r$. It includes 
the temperature of the inner layer, the location of the inner layer, and the characteristic thickness of the oxidation layer and inner layer. Moreover if the ratios $\chi_{\mathrm{q}} / \chi_{\mathrm{q}, 0}$ shown in Figs. 10 and 11 are plotted as a function of $r$, the values are nearly the same for $\mathrm{CO}$ addition to the fuel stream and $\mathrm{CO}$ addition to the oxidizer stream.

\section{Concluding Remarks}

The RRA analysis was carried out to obtain an improved understanding of the influence of addition of $\mathrm{CO}$ on the structure of nonpremixed methane flames. In the present investigation $\mathrm{CO}$ was added either to the fuel stream or to the oxidizer stream with the mass fraction of the reactants so chosen that the calculated value of the stoichiometric mixture fraction, $\xi_{\text {st }}$, and the adiabatic temperature, $T_{\mathrm{st}}$, are the same. The quantity, $Y_{\mathrm{CO}, 1}$ represents the mass fraction of $\mathrm{CO}$ added to the fuel stream and $Y_{\mathrm{CO}, 2}$ the mass fraction of $\mathrm{CO}$ added to the oxidizer stream. The scalar dissipation rate at extinction, $\chi_{\mathrm{q}}$, was predicted and compared with experimental data and with results of numerical computation carried out employing the San Diego Mechanism $[27,28]$. The comparisons were made of predicted values of the ratio $\chi_{\mathrm{q}} / \chi_{\mathrm{q}, 0}$ with the measured values and numerically computed values of $a_{\mathrm{e}} / a_{\mathrm{e}, 0}$ to remove the inaccuracies that are present in predictions of critical conditions of extinction of methane flames without added carbon monoxide. The following remarks summarizes the main findings.

1. Irrespective to which stream $\mathrm{CO}$ is added or the amount of $\mathrm{CO}$, the two-layer structure of the reaction zone, characterized by the oxidation 
layer and the inner layer is maintained. The RRA analysis predicted the slight dependence of the ratio $\chi_{\mathrm{q}} / \chi_{\mathrm{q}, 0}$ on $Y_{\mathrm{CO}, 1}$, that is in agreement with experimental data and computational predictions using detailed chemistry. With increasing amounts of $\mathrm{CO}$ addition to the oxidizer stream, the analysis predicted an increase in value of $\chi_{\mathrm{q}} / \chi_{\mathrm{q}, 0}$ followed by a decrease, also in agreement with measurements and computational predictions.

2. The increase in value of the ratio $\chi_{\mathrm{q}} / \chi_{\mathrm{q}, 0}$ with increasing $Y_{\mathrm{CO}, 2}$ is attributed to the movement of the location of the inner layer toward the fuel boundary. This is consistent with previous asymptotic analysis of the influence of $\xi_{\text {st }}$ on scalar dissipation rate at extinction [31] and numerical computation [24]. In the present analysis this movement is to the first order, while in the previous analysis $[24,31]$ it is to the leading order.

3. There are many similarities between various aspects of the flame structure with $\mathrm{CO}$ addition to the fuel stream stream and $\mathrm{CO}$ addition to the oxidizer stream, when they are plotted as a function of $r$ (defined in Eq. 4). They are shown in Figs. 12, 13, 14, 15 and 16. These figures show the leakages of oxygen and carbon monoxide from the reaction zone to the first order, the temperature at the inner layer, $T^{0}$, the location of the inner layer, and the characteristic thickness of the oxidation layer and the inner layer.

4. While the predictions of $\chi_{\mathrm{q}} / \chi_{\mathrm{q}, 0}$ with increasing $Y_{\mathrm{CO}, 2}$ are in qualitative agreement with experimental data and computational predictions the predicted values of $\chi_{\mathrm{q}} / \chi_{\mathrm{q}, 0}$ with $Y_{\mathrm{CO}, 2}$ agree with experimental data for 
small $Y_{\mathrm{CO}, 2}$ and are significantly smaller than the measurements and computational predictions for large values of $Y_{\mathrm{CO}, 2}$.

5. Results of numerical computations of flame structure obtained using detailed chemistry in Figs. 2, and 3 show that with increasing $Y_{\mathrm{CO}, 2}$ leakages of $\mathrm{O}_{2}$ and $\mathrm{CO}$ increase. This suggests that the approximation introduced in the present asymptotic analysis that $\mathrm{CO}$ and $\mathrm{O}_{2}$ are of the order of $\epsilon \ll 1$ becomes inaccurate for large values of $Y_{\mathrm{CO}, 2}$. Therefore an alternate RRA analysis, that considers $X_{\mathrm{O}_{2}}$ and $X_{\mathrm{CO}}$ are of the order greater than $\epsilon$ in the reaction zone, can improve predictions of $\chi_{\mathrm{q}} / \chi_{\mathrm{q}, 0}$ for large values of $Y_{\mathrm{CO}, 2}$, although this analysis will be inaccurate for small values of $Y_{\mathrm{CO}, 2}$.

\section{Acknowledgments}

The authors would like to acknowledge Professor F. A. Williams for his contributions and helpful discussions. The research at UCSD is supported by the National Science Foundation, award \# CBET-1404026. The research at Lund University is supported by Swedish Research Council (UR).

\section{References}

[1] N. Peters, F. A. Williams, The Asymptotic Structure of Stoichiometric Methane-Air Flames, Combustion and Flame 68 (2) (1987) 185-207.

[2] N. Peters, The Kinetic Foundation of Thermal Flame Theory, in: W. A. Sirignano, A. G. Merzhanov, L. D. Luca (Eds.), Advances in Combustion 
Science -In Honor of Ya. B. Zel'dovich, vol. 173 of Progress in Astronautics and Aeronautics, chap. 5, American Institute of Aeronautics and Astronautics, 73-91, 1997.

[3] N. Peters, Systematic Reduction of Flame Kinetics: Principles and details, in: A. L. Kuhl, J. R. Bowen, J.-C. Leyer, A. Borisov (Eds.), Dynamics of Reactive System Part 1: Flames, vol. 113 of Progress in Astronautics and Aeronautics, chap. II, American Institute of Astronautics and Aeronautics, 67-86, 1988.

[4] N. Peters, Turbulent Combustion, Cambridge University Press, Cambridge, England, 2000.

[5] N. Peters, G. Paczko, R. Seiser, K. Seshadri, Temperature Cross-Over and Non-Thermal Runway at Two-Stage Ignition of N-Heptane, Combustion and Flame 128 (2002) 38-59.

[6] K. Seshadri, F. A. Williams, Reduced chemical systems and their application in turbulent combustion, in: P. A. Libby, F. A. Williams (Eds.), Turbulent Reacting Flows, Academic Press, San Diego, California, 153210, 1994.

[7] K. Seshadri, Multistep Asymptotic Analyses of Flame Structures, Symposium (International) on Combustion 26 (1996) 831-846.

[8] K. Seshadri, N. Peters, Asymptotic structure and extinction of methaneair diffusion flames, Combustion and Flame 73 (1988) 23-44.

[9] K. Seshadri, N. Peters, The Inner Structure of Methane-Air Flames, Combustion and Flame 81 (1990) 96-118. 
[10] B. Rogg, N. Peters, The Asymptotic Structure of Weakly Strained Stoichiometric Methane Flames, Combustion and Flame 79 (1990) 402-420.

[11] K. Seshadri, N. Peters, F. A. Williams, Asymptotic Analyses of Stoichiometric and Lean Hydrogen-Air Flames, Combustion and Flame 96 (1994) 407-427.

[12] H. Pitsch, N. Peters, K. Seshadri, Numerical and Asymptotic Studies of the Structure of Premixed iso-Octane Flames, Symposium (International) on Combustion 26 (1996) 763-771.

[13] X. S. Bai, K. Seshadri, Rate-Ratio Asymptotic Analysis of NonPremixed Methane Flames, Combustion Theory and Modelling 3 (1999) $51-75$.

[14] K. Seshadri, N. Peters, J. A. van Oijen, L. P. H. de Goey, The Asymptotic Structure of Weakly Strained Moderately Rich MethaneAir Flames, Combustion Theory and Modelling 5 (2001) 1-15.

[15] K. Seshadri, N. Peters, G. Paczko, Rate-Ratio Asymptotic Analysis of Autoignition of $n$-Heptane in Laminar Nonpremixed Flows, Combustion and Flame 146 (2006) 131-141.

[16] V. Amin, G. Katzlinger, P. Saxena, E. Pucher, K. Seshadri, The influence of carbon monoxide and hydrogen on the structure and extinction of nonpremixed and premixed methane flames, Proceedings of the Combustion Institute 35 (2015) 955-953.

[17] K. Seshadri, X. S. Bai, Rate-Ratio Asymptotic Analysis of the Influence of Addition of Hydrogen on the Structure and Mechanisms of Extinction 
of Nonpremixed Methane Flames, Combustion Science and Technology 187 (2015) 3-26.

[18] U. Niemann, K. Seshadri, F. A. Wiliams, Effect of Addition of a Nonequidiffusional Reactant to an Equidiffusional Diffusion Flame, Combustion Theory and Modelling 17 (2013) 563-576.

[19] K. Seshadri, F. A. Williams, Laminar flow between parallel plates with injection of a reactant at high Reynolds number, International Journal of Heat and Mass Transfer 21 (2) (1978) 251-253.

[20] J. S. Kim, F. A. Williams, Structures of flow and mixture-fraction fields for counterflow diffusion flames with small stoichiometric mixture fractions, SIAM Journal on Applied Mathematics 53 (1993) 1551-1566.

[21] N. Peters, Laminar diffusion flamelet models in non-premixed turbulent combustion, Progress in Energy and Combustion Science 10 (1984) 319339.

[22] F. A. Williams, Combustion Theory, Addison-Wesley Publishing Company, Redwood City, CA, 2 edn., 1985.

[23] A. Liñán, F. A. Williams, vol. 34 of Oxford Engineering Science Series, Oxford University Press, New York, 1993.

[24] A. Grudno, K. Seshadri, Characteristic Residence Times of Laminar Nonpremixed Flames at Extinction, Combustion Science and Technology, 112 (1996) 199-210. 
[25] M. D. Smooke, Reduced Kinetic Mechanisms and Asymptotic Approximation for Methane-Air Flames, vol. 384 of Lecture Notes in Physics, Springer Verlag, Heidelberg, 1991.

[26] NIST-JANAF Thermochemical Tables, http://kinetics.nist.gov/janaf/, 2013.

[27] P. Saxena, Numerical and Experimental Studies of Ethanol Flames and Autoignition Theory for Higher Alkanes, Ph.d thesis, University of California at San Diego, Department of Mechanical and Aerospace Engineering, 2007.

[28] The San Diego Mechanism, http://combustion.ucsd.edu/, 2009.

[29] Chemkin-Pro 15113, 2012.

[30] M. D. Smooke, V. Giovangigli, Formulation of the Premixed and Nonpremixed Test Problems, in: M. D. Smooke (Ed.), Reduced Kinetic Mechanisms and Asymptotic Approximations for Methane-Air Flames, vol. 384 of Lecture Notes in Physics, chap. 1, Springer Verlag Berlin Heidelberg, 1-28, 1991.

[31] P. Mairhofer, K. Seshadri, X. S. Bai, K. Narayanaswamy, V. Raghavan, Analytical, Experimental and Computational Investigation of the Influence of Stoichiometric Mixture Fraction on Structure and Extinction of Laminar, Nonpremixed Methane Flames and Ethane Flames, in: Paper \# 1B02, 2016 Spring Meeting of the Western States Section Combustion Institute, University of Washington, Seattle, WA, 2016. 


\section{List of Tables}

1 Rate data. Units are moles, cubic centimeters, seconds, kJoules, Kelvin. . . . . . . . . . . . . . . . 15

\section{List of Figures}

1 Predicted profile of temperature, and profiles of mass fractions of $\mathrm{CH}_{4}, \mathrm{CO}, \mathrm{O}_{2}, \mathrm{H}_{2}$ and as a function of $\xi$ with $\mathrm{CO}$ addition to the fuel stream $\left(Y_{\mathrm{CO}, 1}=0.16, T_{\mathrm{st}}=2000 \mathrm{~K}, \xi_{\mathrm{st}}=0.055\right.$,

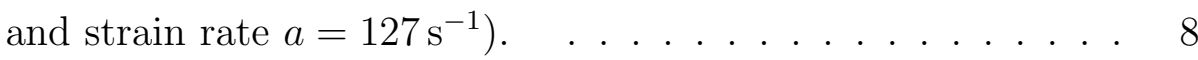

2 Predicted profile of temperature, and profiles of mass fractions of $\mathrm{CH}_{4}, \mathrm{CO}, \mathrm{O}_{2}, \mathrm{H}_{2}$ and as a function of $\xi$ with $\mathrm{CO}$ addition to the oxidizer stream $\left(Y_{\mathrm{CO}, 2}=0.12, T_{\mathrm{st}}=2000 \mathrm{~K}, \xi_{\mathrm{st}}=0.055\right.$,

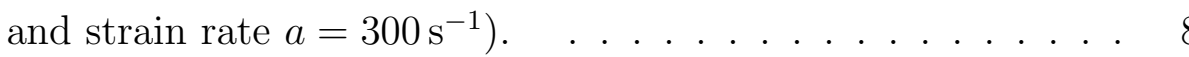

3 Predicted profile of temperature, and profiles of mass fractions of $\mathrm{CH}_{4}, \mathrm{CO}, \mathrm{O}_{2}, \mathrm{H}_{2}$ and as a function of $\xi$ with $\mathrm{CO}$ addition to the oxidizer stream $\left(Y_{\mathrm{CO}, 2}=0.19, T_{\mathrm{st}}=2000 \mathrm{~K}, \xi_{\mathrm{st}}=0.055\right.$,

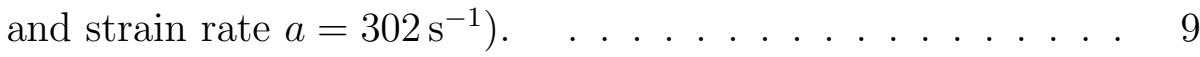

4 Predicted values of mass fractions of $\mathrm{CH}_{4}, \mathrm{CO}, \mathrm{O}_{2}$, and $\mathrm{H}_{2}$ at $\xi_{\mathrm{st}}=0.055$ as a function of mass fraction of $\mathrm{CO}$ in the oxidizer stream, $Y_{\mathrm{CO}, 2}$ at conditions close to flame extinction. . . . . . 10

5 Schematic illustration of the outer structure with CO addition to the fuel stream and to the oxidizer stream. . . . . . . 13

6 Schematic illustration of the reaction zone structure around $\xi_{\text {st }}$. The figure shows the inner layer and the oxidation layer. . 17 
7 The flame temperature, $T^{0}$, as a function of $\left(\chi^{0}\right)^{-1}$ for $\mathrm{CO}$ addition to the oxidizer stream, with $Y_{\mathrm{CO}, 2}=0.02 \ldots . .26$

8 The normalized mass fraction of $\mathrm{O}_{2}, X_{\mathrm{O}_{2}}^{0}$, as a function of $\left(\chi^{0}\right)^{-1}$ for $\mathrm{CO}$ addition to the oxidizer stream, with $Y_{\mathrm{CO}, 2}=0.0227$

9 The characteristic thickness of the oxidation layer, $\epsilon$, as a function of $\left(\chi^{0}\right)^{-1}$, for CO addition to the oxidizer stream, with $Y_{\mathrm{CO}, 2}=0.02 \ldots \ldots \ldots \ldots \ldots \ldots$

10 The ratio $\chi_{\mathrm{q}} / \chi_{\mathrm{q}, 0}$ at extinction for various values of $\mathrm{CO}$ added either to the oxidizer stream, or to the fuel stream, at fixed $T_{\mathrm{st}}=2000 \mathrm{~K}$, and $\xi_{\mathrm{st}}=0.055$. The lines are predictions of the asymptotic analysis, the broken lines are computational predictions obtained using the San Diego Mechanism [16] and the symbols are measurements $[16]$. . . . . . . . . . . . . 29

11 The ratio $\chi_{\mathrm{q}} / \chi_{\mathrm{q}, 0}$ at extinction for various values of $\mathrm{CO}$ added either to the oxidizer stream, or to the fuel stream, at fixed $T_{\mathrm{st}}=2100 \mathrm{~K}$, and $\xi_{\mathrm{st}}=0.055$. The lines are predictions of the asymptotic analysis, the broken lines are computational predictions obtained using the San Diego Mechanism [16] and the symbols are measurements [16]. . . . . . . . . . . . . . . . 30

12 The value of $z_{\mathrm{O}_{2}}^{0}$ at extinction obtained from numerical integration of Eq. (21) as a function of $r$. The symbols are for CO addition to the fuel stream and the lines for $\mathrm{CO}$ addition to the oxidizer stream. . . . . . . . . . . . . . . . . 32 
13 The value of $z_{\mathrm{CO}}^{0}$ at extinction obtained from numerical integration of Eq. (21) as a function of $r$. The symbols are for CO addition to the fuel stream and the lines for $\mathrm{CO}$ addition to the oxidizer stream. . . . . . . . . . . . . . . . . . . . . . 32

14 The value of the temperature at the inner layer at extinction, $T^{0}$ as a function of $r$. The symbols are for CO addition to the fuel stream and the lines for $\mathrm{CO}$ addition to the oxidizer stream. 33

15 The predicted location of the inner layer at extinction, $\eta^{0}$, as a function of $r$. The symbols are for $\mathrm{CO}$ addition to the fuel stream and the lines for $\mathrm{CO}$ addition to the oxidizer stream. . 34

16 Predicted value of $\delta$ and $\epsilon$ at extinction as a function of $r$. The symbols are for $\mathrm{CO}$ addition to the fuel stream and the lines for $\mathrm{CO}$ addition to the oxidizer stream. . . . . . . . . . . . 35 